\title{
Chitosan Mediated Targeted Drug Delivery System: A Review
}

\author{
Manish P. Patel *, Ravi R. Patel, Jayvadan K. Patel
}

Department of Pharmaceutics, Nootan Pharmacy College, Visnagar-384315, Gujarat, India. Recievd, September 13, 2010; Revised, October 30, 2010, Accepted, November 3, 2010; Published November A, 2010.

ABSTRACT - Chitosan has prompted the continuous movement for the develop nt o afe nd effect drug delivery systems because of its unique physicochemical and biological ch acteristics. e primar h uroxyl and amine groups located on the backbone of chitosan allow for chemical dification control physical properties. When the hydrophobic moiety is conjugated to a chitos n molec the result mphiphile may form self-assembled nanoparticles that can encapsulate a quanty of angs and liver them a specific site of action. Chemical attachment of the drug to the chitosan th ughout the functio linker may produce useful prodrugs, exhibiting the appropriate biological activity the target site. N coadhesive and absorption enhancement properties of chitosan increase the in vivo resic ce time of the dosage form in the gastrointestinal tract and improve the bioavailability of various dr. The ma objective of this review is to provide an insight into various target-specific carriers, based on chito and is revatives. The first part of the review is concerned with the organ-specific deth systerpasing hitosan and its derivatives. The subsequent section considers the recent developmer. of $\mathrm{dr}$ delive $\mathrm{y}$ carrie for cancer therapy with special focus on various targeting strategies.

\section{INTRODUCNION}

Drug di ver and develc

Tengir laborioul, and expensive processes.

M of th trugs in the clinical phase, however, fai to achie Gyorable clinical outcomes because ney not buve the ability to reach the target site faction A significant amount of the administrated is distributed over the normal tissues or organs that are not involved in the pathological process, often leading to severe side effects. An effective approach to overcome this critical issue is the development of targeted drug delivery systems that release the drugs or bioactive agents at the desired site of action. This could increase patient compliance and therapeutic efficacy of pharmaceutical agents through improved pharmacokinetics and biodistribution [1-4].

The idea of developing a drug that selectively destroy disease cells without damaging healthy cells was proposed by Paul Ehrlich, almost a century ago; he called his hypothetical drug the "magic bullet" [5]. Thereafter, over the past several decades, many scientists have focused their attention on the development of ideal drugs that specifically target the site of action. Although little progress has been made in this field, the advent of nanomedicine and our understanding of cellular and molecular biology have opened new avenues to transform the Ehrlich's concept into clinical reality [6]. The targeted drug delivery system is comprised of three components: a therapeutic agent, a targeting moiety, and a carrier system. The drug can be either incorporated by passive absorption or chemical conjugation into the carrier system. The choice of the carrier molecule is of high importance because it significantly affects the pharmacokinetics and pharmacodynamics of the drugs.

A wide range of materials, such as natural or synthetic polymers, lipids, surfactants and dendrimers, have been employed as drug carriers [7-10]. Among these, polysaccharides have received increasing attention because of their outstanding physical and biological properties [11]. Chitosan, a linear aminopolysaccharide composed of randomly distributed $(1 \rightarrow 4)$ linked Dglucosamine and N-acetyl-D-glucosamine units, is obtained by the deacetylation of chitin, a widespread natural polysaccharide found in the exoskeleton of crustaceans such as crab and shrimp [12].

Corresponding Author: Mr. Ravikumar R Patel, Assistant Professor, Department of Pharmaceutics, Nootan Pharmacy College, S.P.Sahkar Vidhyadham, Kamana Crossing, Visnagar Email: raviptl 84@yahoo.co.in 
This cationic polysaccharide has drawn increasing attentionwithin pharmaceutical and biomedical applications, owing to its abundant availability, unique mucoadhesivity, inherent pharmacological properties, and other beneficial biological properties such as biocompatibility, biodegradability, nontoxicity and low-immunogenicity [12-14]. The physicochemical and biological properties of chitosan are greatly influenced by its molecular weight and degree of deacetylation. Detailed characteristics of chitosan for biomedical applications arewell described in several comprehensive reviews [12-14]. The presence of reactive functional groups in chitosan offers great opportunity for chemical modification, which affords a wide range of derivatives such as quaternized chitosan (N,N,N-trimethyl chitosan; TMC), carboxyalkyl chitosan, thiolated chitosan, sugar-bearing chitosan, bile acid-modified-hitosan and cyclodextrin-linked chitosan [1-20]. rious synthetic strategies for the mation of the chitosan have been extensirely review ers ere $[12,21,22]$. These chitosa derivatives ve bu designed to improve specil properties native chitosan. For example, th ation of chitosan remarkabl mprgves its muce thesive properties because of fo mation of di sifide bonds with eystu -rich bdomain of mucus glycoproteins 23]. I e chem 1 modi.cation of chitosan imparts $\mathrm{ph}$ - ilicity, is an important characteristic fo the ation of self-assembled nanoparticles, po tially suited for drug delivery applications. The curophobic cores of the nanoparticles could act as reservoirs or microcontainers for various bioactive substances. Because of their small size, nanoparticles can be administrated via the intravenous injection for targeted drug delivery. Conjugation of the targeting moieties to the surface of drug-loaded nanoparticles may improve therapeutic efficiency of the drug [24]. Chitosan has been widely utilized as drug delivery systems for low molecular drugs, peptides and genes $[16,25$, 26]. Despite the recent emergence of biomacromolecular drugs, the majority of therapeutic drugs that are being developed and marketed are primarily low molecular weight drugs. Recent comprehensive surveys also disclosed that many molecular targets have been explored for therapeutic interventions, and most of the drugs approved for these targets are from small molecules [27]. Hence, the successful delivery of low molecular drugs to their respective targets is still of prime important in therapeutics.

The primary focus of this review is to provide an insight into various target-specific drug carriers based on chitosan and its derivatives. The first par of the review deals with organspecif telivery using chitosan and its derivatives In su quent sections we discuss the recent brogress in ch sanbased drug carriers for cance herapy with $s_{1}$ ial focus on various targeting strate

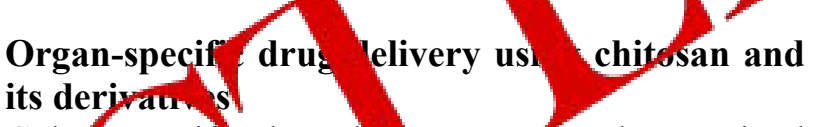
its derivatm - specific drug do ery systems have gained incr asing attention for treatment of diseases suc as Crohn's disease, ulcerative colitis, and irrita bowel syndrome [28,29]. Colon targeting has $P$ seful for systemic delivery of otein/peptide drugs because of the relatively low p r Hytic activities in the colon and even for other nonpeptide drugs such as cardiovascular and antiasthmatic agents. Several strategies are currently pursued for colon-targeted delivery, including the use of prodrugs that becomeactive at the colon, drug-eluting system responding to the $\mathrm{pH}$, andmicro.ora-activatable drug delivery systems. The major obstacles in delivering drugs to the colon are the absorption and degradation pathways in the upper gastrointestinal tract. Hence, all the above strategies have attempted to prevent loss of the drug at the stomach and the small intestine, thereby facilitating quantitative drug delivery to the colon.

Chitosan-based delivery systems have been widely studied for colonic drug targeting since this system can protect therapeutic agents from the hostile conditions of the upper gastrointestinal tract and release the entrapped agents speci.cally at the colon through degradation of the glycosidic linkages of chitosan by colonic micro.ora [30,31]. Yamamoto et al. investigated the use of chitosan capsules for colon-specificdelivery of 5aminosalicylic acid (5-ASA) [32]. The surface of the chitosan capsules containing 5-ASA was coated with hydropropyl methylcellulose phthalate as an enteric coating material. The experimental results demonstrated that the capsules were able to reach the large intestine $3.5 \mathrm{~h}$ after oral administration into 2,4,6-trinitrobenzenesulfonic acid-induced ulcerative rats. The release of 5-ASA from the capsule was markedly increased in the presence of 
rat cecal contents. Chitosan capsule-based formulations showed better therapeutic effect than a carboxymethylcellulose suspension in vivo. Chitosan capsules can also be used as carriers for colon-specificdelivery of absorption enhancers. Oral delivery of the absorption enhancer along with poorly absorbable drugs using chitosan capsules could improve the absorption characteristics of the drugs [33]. Varshosaz et al. reported chitosan microspheres coated with cellulose acetate butyrate, prepared by the emulsion-solvent evaporation technique, for delivery of 5-ASA into the colon [34]. The authors found that decreasing the coat content and increasing the molecular weight of chitosan increased its bioadhesion significantly. Chitosan-Ca-alginate microparticles have also been used for colon specific delivery of 5-ASA [35]. The microparticles were prepared using the spray drying method, followed by ionotropic gelation/ polyelectrolyte complexation. In vitro drug-release experiments carried out under conditions similar to colon exhibited controlled release behavior of the drug. Biodistribution studies of an-Caalginate microparticles loaded w-131 -ASA showed localization of 5-ASA the on $y$.th low systemic bioavailability Recently, in al. prepared hydrogel miross res of chito n gran with vinyl polymars for the ntrolled an argeted delivery of 5 -ASA to the ce n, which exhibited better ther uticjeffects [36].

Chitosa has often been mited in colonic targo $g$ of c gs becau e of its high solubility in astri uids, so times resulting in burst release of at the nach. Although chitosan can be ii lubla actdic uids through chemical crosslin $g$ of the microsphere with aldehydes, it is not effe ve in preventing the release of the encapsulated drugs. To alleviate this problem, Alonso et al. developed microencapsulated chitosan microspheres coated with enteric coating materials [37]. The potential of this microsphere was evaluated using sodium diclofenac (SD), an antiin.ammatory drug. SD was entrapped into the chitosan cores by the spray drying method, after which the chitosan cores were microencapsulated into Eudragit ${ }^{\circledR}$ L-100 and Eudragit ${ }^{\circledR}$ S-100 using an oil-in-oil solvent evaporation method. The in vitro release studies revealed that no $\mathrm{SD}$ was released at the gastric $\mathrm{pH}$; however, when the microsphere reached the colonic environment, a continuous release was observed for a variable time
(8-12 h). In a similar study, Onishi et al. prepared Eudragit $\AA$-coated microspheres composed of chitosan-succinylprednisolone conjugates (Ch-SP) using the sonication method [38]. These authors demonstrated that Eudragit ${ }^{\circledR}$-coated microspheres protected the $\mathrm{Ch}-\mathrm{SP}$ microspheres from morphological changes at $\mathrm{pH} 1.2$, and regenerated them at $\mathrm{pH} 6.8$ and 7.4. The release of prednisolone was suppressed at $\mathrm{pH} 1.2$, whereas gradual releaso of the drug was observed at $\mathrm{pH} 6.8$, inc ting the potential of the coated minsphe for specificdelivery systems of the drug to the plon. Jain et al. developed hito $n$ h drogel ds, exhibiting pH-sensitiva poparties a specificbiodegrada ty for colo argeted elivery of satranidas le [3 The chit $n$ beads were prepared by he chem cross-link g, followed by ente c coating with Et agit ${ }^{\circ}$ S-100. The results exl ited that Eudragi $\$ 100$ coating on the chi an beads prevented the premature drug release in si lated upper gastrointestinal conditions. As a consec most of the loaded drugs were leased in the colon, an environment rich in bo ríal enzymes that degrade the chitosan. Chourasia et al. prepared a similar multiparticulate system by coating cross-linked chitosan microspheres with Eudragit ${ }^{\circledR}$ L-100 and S-100 as $\mathrm{pH}$-sensitive polymers, for targeted delivery of metronidazole, a broad-spectrum antibacterial agent [40]. In vitro drug-release studies were performed in conditions simulating stomach-to-colon transit in the presence and absence of rat cecal contents. The results showed a $\mathrm{pH}$-dependent release of the drug attributable to the presence of the Eudragit ${ }^{\circledR}$ coating. Moreover, the release of drug was found to be higher in the presence of rat cecal contents, indicating the susceptibility of the chitosan matrix to colonic enzymes. Similar nanoparticular systems for colon-specificdelivery of metronidazole were reported by Elzatahry and Eldin [41]. Hyaluronic acid-coupled chitosan nanoparticles bearing 5.uorouracil (5-FU) were also prepared by an ionotropic gelation method for the effective delivery of the drug to the colon tumors [42]. These nanoparticles showed enhanced cellular uptake by HT-29 colon cancer cells compared to the uncoupled nanoparticles. The cytotoxicity of 5-FU incorporated in nanoparticles was higher compared to the free 5-FU solution. 


\section{Liver-targeted drug delivery}

The liver is a critical target tissue for drug delivery because many fatal conditions including chronic hepatitis, enzyme de.ciency, and hepatoma occur in hepatocytes. In general, liver-targeting systems employ passive trapping of microparticles by reticuloendothelium or active targeting based on recognition between hepatic receptor and ligandbearing particulates [43]. Machida et al. evaluated the potential of lactosaminated $\mathrm{N}$-succinyl-chitosan (Lac-Suc), synthesized by reductive amination between N-succinyl-chitosan and lactose in the presence of sodium cyanoborohydride, as a liverspeci .c drug carrier [44]. When Lac-Suc labeled with FITC was intravenously injected into mice, it initially underwent fast hepatic clearance and showed maximum liver localization at $8 \mathrm{~h}$. The specific binding of Lac-Suc to the asialoglycoprotein receptors, which are found at the liver parenchymal cells, was also examined using competitive binding studies with asialofetuin in vivo. The results revealed that the liver uptake of Lac-Suc was inhibited by asialofetuin, and it was suggested that the liver distribution on ac-Suc should be concerned with the a oglyo rotein receptor. In another study, thean hor em atrated the targeting ability Lac-Suc metastatic stage of li-er ca er [45].

Recently, J ei al. pro red polyior omplex micelles (PIC micelles) bas on methoxy poly (ethylene col) (PEG)-grafto osan and lactoseconingated Ee-graft-chitosa for liver-targeted deliv $y$ of di monium glycyrrhizinate (DG) [46]. $\mathrm{DG}$ as been ed $i$ the treatment of chronic pan and munode.ciency virus infection. 1 rmaco etic experiments carried out using rats sh ed that the area under the curve (AUC) values of $G$ for PIC micelles were higher than that for DG injection. The lactose-conjugated PIC (LacPIC) micelles delivered more DG to the liver than conventional PIC micelles, indicating that Lac-PIC micelles were promising livertargeted nanocarriers for DG. Ping et al. conjugated glycyrrhizin (GL) to the surface of chitosan nanoparticles (CS-NP)s, prepared by an ionic gelation process [47]. These nanoparticles were developed for a drug delivery system targeting the liver through a specific interaction between GL and hepatocytes. In this study, adriamycin, chosen as the model drug, was encapsulated into the nanoparticles. The loading ef.ciencies of the drug for CS-NPs and GL-modi.ed nanoparticles (GLCS- NPs) were 65.5\% and 91.7\%, respectively. The higher loading ef.ciency of GLCS-NPs was attributed to the ionic interaction between adriamycin and oxidized GL. Flow cytometry and confocal laser microscopy studies exhibited preferential accumulation of GLCS- NPs in hepatocytes. The cellular uptake of GL-CS-NPs was dependent on incubation time and dose of nanoparticles, suggesting that internalization of these nanoparticles into hepatocytes wos mostly mediated by a ligand-receptor interaction

\section{Kidney and lung targeted $d$ ivery}

Kidney-targeted drug eliv is critical attempting to reduc extra-rena xicity of the ug and to improve/ts rapeutic en ency for liseases occurring int the $\mathrm{k}$ ey. It ma he particularly bene cial to drugs ch as no -steroidal antiin.? hmatory drugs (Ns IDS) [48]. The mesangial ce of the glomerulus an proximaltubular cells, an he interstitial broblasts are principal targets for rena ug deliy ry since they play a pivotal role in many processes in the kidney. Several ategies have been proposed for drug targeting to th kidney in the form of drug-carrier conjugates [49-51]. However, these systems often suffer from renal toxicity, cardiovascular side effects, and poor biocompatibility [52,53]. Therefore, researchers have devoted their efforts in developing highly safe carrier systems for the drugs. Recently, Zhang et al. reported that randomly $50 \% \mathrm{~N}$-acetylated low molecular weight chitosan (LMWC) selectively accumulated in the kidneys, especially in the renal tubes after intravenous injection into mice [54]. In an attempt to develop drug delivery system for renal targeting, the authors conjugated prednisolone to LMWC (19 kDa) through a succinic acid spacer. The distribution of the conjugates in the kidney was found to be 13 fold higher than that of prednisolone alone. It was concluded that LMWC with a proper molecular weight could be applied as a promising carrier for renal targeting. In an additional study, the site-specific uptake of LMWC was found to be mediated by the megalin receptor whose ligand shares a similar glucosamine unit level with LMWC [55]. To elucidate the exact mechanism behind the selective accumulation of LMWC in the kidney, the renal uptake process of LMWC was investigated. A megalin-shedding animal model along with the competitive inhibition assay con.rmed that after selective accumulation of LMWC in the kidney, 
LMWC was speci.cally taken up by renal tubular cells, where the megalin receptor mediated its binding and uptake.

Lung cancer is one of the most prevalent cancers and is the leading cause of cancer mortality in the developed world [56]. In particular, nonsmall cell lung cancer (NSCLC) accounts for approximately $80 \%$ of all lung cancers. Delivering drugs to the lungs has many advantages over others because lungs have a large alveolar surface area, thin epithelial barrier, extensive vascularization and relatively low enzymatic metabolic activity [57]. Intravenous injection of microspheres and inhalation are the possible administration routes for targeting drugs to the lungs. However, some studies have shown that microspheres with a particle diameter greater than 5 ìm could block blood capillaries and induce chronic obstructive pulmonary emphysema [58]. On the other hand, frequent inhalation may induce lung .brosis [59] Hence, designing a proper carrier system is essential for successful delivery of the drug to the lung. Paclitaxel has shown signi.nt a ity in advanced NSCLC. Recently, Shim al. epared chitosan-modi.ed poly(lactic-obgl lis acid) nanoparticles contain paclitax paclitaxel) with a $n$ an dia eter of $200-0$ nm by a solvent exaponation me d [60]. é study demonstr $d$ that the in ro uptake of the nanopartic by lung cancer 1 line (A549) was so antly reased by chitosan modi.cation. In parti lar, a lung-s ccific increase in the istr nution de of paclitaxel (i.e., C(n ) aU (plasma)) was observed for CA pachinuel, when administered to lungme resized mice via the tail vein at a paclitaxel dose of $10 \mathrm{mg} / \mathrm{kg}$. Transient formation of nanoparticular aggregates in the bloodstream, followed by enhanced trapping in the lung capillaries, was proposed as the mechanism of lung tumor-specific distribution of C-NPs-paclitaxel. Also, the authors showed that under acidic tumor conditions, C-NPs became more positive and interacted strongly with the negatively charged tumor cells [61]. The enhanced interaction between C-NPs and tumor cells at the acidic microenvironment might be the underlying mechanism of lung tumor-specific accumulation of paclitaxel from C-NPs-paclitaxel.

\section{Cancer-targeted drug delivery using chitosan} and its derivatives

The critical bottleneck of conventional cancer chemotherapeutics includes high toxicity of most anticancer drugs, due to indiscriminate distribution of drugs towards disease and healthy cells following systemic administration. In addition, anticancer drugs often suffer from poor solubirity water and thus need to use organic vents or detergents for clinical applications, re ting in undesirable side effects such as vehous itation and respiratory distress [62] herefore, desi ing a distinct carrier systen hat car ulates a coe quantity of drugs d speci.call argets tu nop cells is indispensa e for ccessful ca er ther py.

Pas ive targeting - hanced permeability and re ntion (EPR) effect

$\mathrm{Tl}$ origin of the EPR concept dates back to the late 19 when Mada et al. discovered the selective accu ation of macromolecular drugs in tumor tissues [0s,04]. The specificpassive accumulation of aromolecules was attributed to defective tumor yasculature with disorganized endothelium at the tumor site and a poor lymphatic drainage system. Since then, researchers have capitalized this concept for the delivery of various drugs by conjugating them with polymers or encapsulating within nanoparticles. Nowadays, it is evident that long circulating macromolecules (polymer-drug conjugates) and nano-sized particulates (such as micelles and liposomes) accumulate passively at the tumors due to the EPR effect [7].

\section{Chitosan-drug conjugates}

In 1975, Ringsdorf .rst proposed the concept of polymer-drug conjugates for delivering hydrophobic small molecular drugs to their site of action [65]. The polymer-drug conjugates are composed of a water-soluble polymer that is chemically conjugated to a drug via a biodegradable spacer. The spacer is usually stable in the bloodstream but cleaved at the target site by hydrolysis or enzymatic degradation. Such drug conjugates can be selectively accumulated at the tumor site by the EPR effects, followed by release of the drug by cleavage of the spacer. Based on this concept, several polymer-drug conjugates have recently entered into phase I/II clinical trials. The representative example is $\mathrm{N}$-(2-hydroxypropyl) methacrylamide (HPMA) copolymer-based drug 
conjugates such as HPMA copolymer-doxorubicin conjugate (PK1) and HPMA copolymerdoxorubicin conjugate containing galactosamine as a targeting moiety (PK2), developed for the treatment of primary or secondary liver cancer [66].

In recent years, chitosan-anticancer drug conjugates have also been investigated, as shown in Fig. 1. For example, doxorubicin-conjugated glycol chitosan (DOX-GC) with a cis-aconityl spacer was synthesized by chemical attachment of N-cisaconityl DOX to GC using carbodiimide chemistry [67]. DOX-GC conjugates containing 2-5 wt.\% DOX formed self-assembled nanoparticles in an aqueous condition, but those that contained DOX above 5.5 wt.\% precipitated because of increased hydrophobicity. It is of interest to note that the hydrophobic nature of DOX within the conjugate allowed for its physical entrapment inside the nanoparticles. The loading contents of DOX in the nanoparticles increased up to 38.9 wt.\%. The release rate of DOX from the nanoparticles was signi.cantly dependent on the $\mathrm{pH}$ of the media because the cis-aconityl spacer is readily cleavable at a low $\mathrm{pH}$. When the DOX-GC nanoparticles were systemically administrated into the mice, they preferentially accumulated into the tumo tissue, ascribed to the EPR effect [67]

Low molecular weight enitosan co ig with paclitaxel (LMWC-PTX) as also syi esize chemical conjugatio of LM $\mathrm{VC}$ and PT, hrough a succinate linker, which $\mathrm{n}$ be cl ved at physiolog 1 conditions $(h-1)$ [68]. This conjugate s e qluated as a firer for the oral der. $y$ of aclitaxel. LMWC $(\mathrm{MW}<10 \mathrm{kDa})$ exhib mor avorab characteristics than high ole har weig bitosan, such as lower toxicity a water solubility.Moreover, LMWC co d quirkly and reversibly open the tight jun ris between human epithelial colorectal adenocarcinoma cells (Caco-2). This is a highly useful characteristic for a carrier of drug molecules, especially for oral delivery. LMWC-PTX was absorbed in the small intestine after oral administration and remained in its intact conjugate form until it reached the bloodstream. An advantage of LMWC-PTX for oral delivery of PTX is that LMWC-PTX has the ability to bypass the Pgpmediated barrier (ef.ux pump) in the gastrointestinal tract and CYP450-dependent metabolism in the intestine and liver [68]. N- succinyl-chitosan derivatives were conjugated with mitomycin $\mathrm{C}$ (MMC) using carbodiimide chemistry [69]. Owing to the hydrophilicity of N-succinylchitosan, the conjugate is water-soluble when the MMC content in the conjugate is less than $12 \%$. The N-succinylchitosan conjugates exhibited good antitumor activities against various tumors such as murine leukaemias (L1210 and P388), B16 melanoma, Sarcoma 180 solid tumor, a murine liver metastatic tumor (M5076), and a murine hepatic cell carcinoma (MH134) [70].

Cross-linked chitosan nanoparticln

Chitosan and its derivatives can be co lently cross-linked to prepare nan ized particles the drug carriers [71]. Fig. 2 w the che al reactions between hitosan an functiona chosslinkers. Th cro linking cess involves formation the of alent bon between the chits san chams and fu tional cross-linking agents. $\mathrm{Th}$ representative chen 1 cross-linkers that have be widely used for cbhosan include bi-functional age such as PEG dicarboxylic acid, gluta lehyde or monofunctional agents such as vichloronyarin $[72,73]$.

Eor the preparation of chitosan particles, several tenniques are available such as emulsion, ionotropic gelation, reverse micellar, solvent evaporation, spray drying, coacervation, and sieving methods [74-76]. A variety of hydrophilic and hydrophobic drugs can be loaded into the chitosan nanoparticles during the preparation of the nanoparticles, in which the loading ef.ciency of the drug may depend on its physicochemical characteristics and the preparation method. The detailed methods for preparation of chitosan microand nanoparticulate systems have been extensively reviewed elsewhere [71,76]. For cancer therapy, a hydrophilic 5-.uorouracil was successfully loaded into chitosan nanoparticles $(250-300 \mathrm{~nm}$ in diameter) using the water-in-oil emulsion method, followed by chemical crosslinking of the chitosan in the presence of glutaraldehydes [74]. Mitra et al. encapsulated doxorubicin conjugates into crosslinked chitosan nanoparticles using the reverse micellar method [77]. The antitumor effect of the resulting nanoparticles was evaluated in J774A.1 macrophage tumor cells implanted subcutaneously in Balb/c mice. 


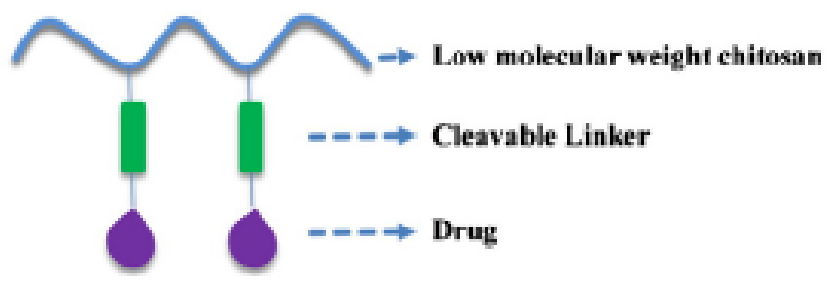

a

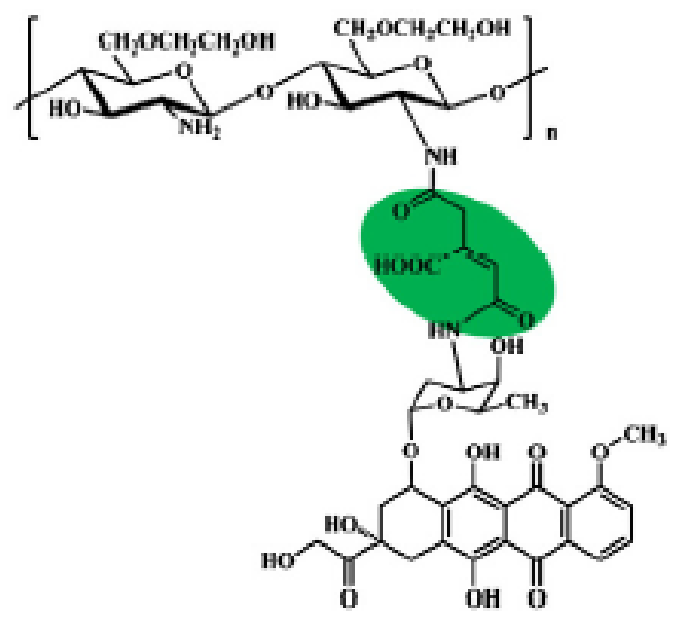

b
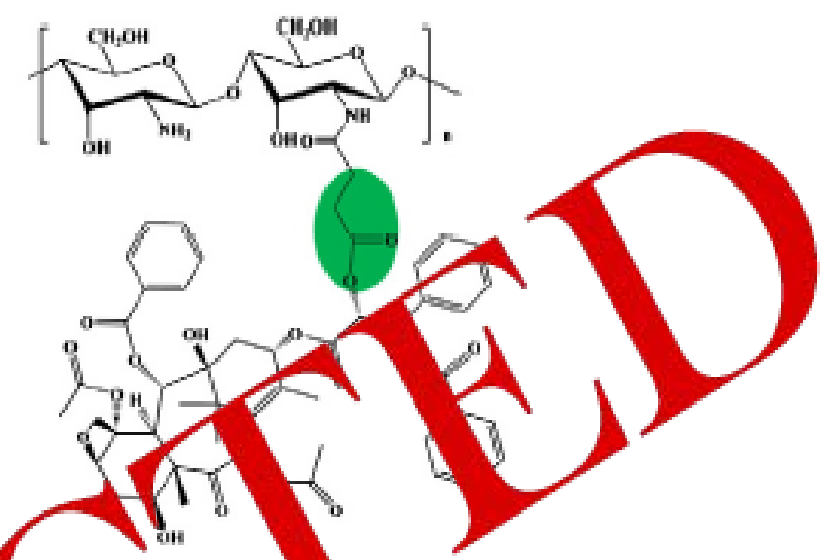

Figure 1. Schematic representation of the chitosan-drug o njugate be $\mathrm{g}$ the cleavable linker. Chemical structure of (a) glycol chitosan-doxorubicin conjugate with the cis-aco linkage (b) cb/osan-paclitaxel conjugate with the succinate linkage.

The drug conjugate-encapsuated exhibited enhanced tumen ression the conjugates itself, and te nan articular fo ulation showed better penfolmance relation orife expectancy

The ion lly ross-linked oparticles have often $\mathrm{p}$ ared using the chitosan and its erivat es by ploiting heir cationic nature, in ich ne amino oups of the chitosan backbone ca Inu wit salts such as sodium sulfate, trip vphospute (TPP), or other multiple-charged anio molecules [77]. The ionic cross-linking of chitosan is advantageous since the process is simple and often carried out under mild conditions without using organic solvents. Ionotropic gelation of chitosan using TPP for the encapsulation of drugs was .rst demonstrated by Bodmeier et al. [78] who intended to the preparation of chitosan beads. Later, Alonso et al. developed the preparation technique of chitosan nanoparticles, immediately formed through ionic interactions between the negatively charged phosphates of TPP and positively charged amino groups of chitosan [75]. Thereafter, TPP-crosslinked chitosan nanoparticles have been widely

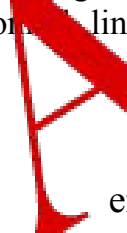

employed to deliver various small molecular drugs and biomacromolecular therapeutics. For example, Janes et al. effectively entrapped DOX into the chitosan nanoparticles during ionotropic gelation of the chitosan with TPP [79]. The cytotoxicity results of DOX-loaded nanoparticles in human melanoma A375 cells and C26 murine colorectal carcinoma cells indicated that nanoparticular formulations containing dextran sulfate were able to maintain cytostatic activity relative to free DOX. In addition, the confocal microscopy studies supported that DOX-loaded nanoparticles are internalized by cells and degraded intracellularly to release the drug.

\section{Chitosan-based polyelectrolyte complex (PEC) nanoparticles}

PECs, prepared by electrostatic interactions between oppositely charged polyions, have received considerable attention as carrier systems for drug and gene delivery [80-82]. The complex formation and the physical properties of PECs are in.uenced by many factors such as degree of ionization of the chitosan and anionic counterparts, chain exibility, charge distribution over the polymer chain, $\mathrm{pH}$, 
temperature, time of interaction, ionic strength, and concentration of the polymeric solutions [83]. The preparation of PEC nanoparticles is quite simple and can be easily performed under mild conditions without the use of toxic organic reagents. It has been demonstrated that chitosan can form PEC nanoparticles with various polyanions such as hyaluronic acid, chondroitin sulfates, alginate, carboxymethyl cellulose, carrageenan, heparin, and poly(acrylic acid) [84-86]. Recently, chitosan has been investigated as the carrier of a hydrophilic 5FU by forming PEC nanoparticles with polyaspartic acid sodium salt [87]. The drug-loaded nanoparticles showed sustained release of 5-FU both at the in vitro and in vivo conditions, compared to the pure 5FU solution. From the in vivo animal test, it was found that the tumor inhibition rate of PEC nanoparticles is much higher than that of 5-FU alone [88]. Cafaggi et al. prepared and evaluated the potential of PEC nanoparticle formed between anionic alginate and cationi chitosan or N-trimethyl chitosan as a narticulate formulation for cisplatin [89]. The part the nanoparticles was in the rango $f 180$ and the surface can be tunea to positive depending on e polyelec lyte ve ratios. The resultir nano ticles relea d cisplatin in a sustained manner in a $3 \mathrm{~S}(\mathrm{pH}=7.4$ Cheng et al. have vestigated the pot ial of DNA/chitosan nanocom, xes as a carrier DOX [90]. They a. sed in ivo biodlstribution of FITC-chitosan and DNA/ TC-chity an nanocomplexes after intr renous in tion to the mice. After $24 \mathrm{~h}$ postyjec. the oNA/FITC-chitosan nanocomplexes re acounulated into the liver and kidney and ro ined at a relatively high stable level in blood, wrile the uorescence intensity of free FITCchitosan decreased rapidly within $4 \mathrm{~h}$ postinjection. From in vitro cytotoxicity test, it was con.rmed that DNA/chitosan-DOX conjugate exhibited cytotoxic effects on HeLa, HepG2, QGY7703, and L02 cells. Hu et al. prepared hollow nanosphere based on chitosan-poly (acrylic acid) (CS-PAA) as a carrier of DOX [91]. The in vitro cytotoxicity of DOX-loaded CS-PAA hollow nanospheres against $\mathrm{HpG} 2$ cells was comparable to the free DOX. The potential of folateconjugated PEC nanoparticles as targeted drug carrier was estimated by the cellular uptake behavior of the complex, formed between folate-conjugated poly-ãglutamic acid (ã-PGA-FA) and FITC-labeled chitosan (CS-FITC), using A2780/AD ovarian cancer cells which overexpress folate receptors [92]. The confocal microscopic images revealed that the folate-bearing nanoparticles were readily taken up by the cells within $60 \mathrm{~min}$.

\section{Self-assembled chitosan nanoparticles}

Polymeric amphiphiles can form selfnanoparticles (SNPs) in an aqueous vironmen via hydrophobic interactions bet en the hydrophobic parts, primarily to minimize erfacial free energy. Since chitoo is a hydroph and cationic polysacchariu, $c h$ an ased SN con be readily obta d by che ally atta hig the hydrophobi mol to the ba bone chitosan and its ivatives, shown in 5 . These SNPs car circulate in the $b$ dstream for a relatively long ti e without recogni by phagocytes and can e ily accumulate $\mu$ the leaky vasculature th yhout the EPR effect [93,94]. Enhanced acc rlation at the tumor site can be achieved by conjuganng the targetingmoiety to the SNPs (Fig. Owing to the insoluble nature of chitosan $\mathrm{pKa}=6.4)$ in water, the SNPs from chitosan amphiphiles are rapidly precipitated in a biological solution ( $\mathrm{pH}$ 7.4).

Therefore, water-soluble chitosan derivatives have often been applied for development of SNPs in drug delivery systems [25,95-97]. For chemical conjugation of the hydrophobic moiety, the primary hydroxyl and amine groups of chitosan have been utilized using various synthetic routes. Numerous hydrophobic moieties have been used for development of amphiphilic chitosan derivatives such as bile acids (e.g., 5â- cholanic acid, cholic acid and deoxycholic acid) and fatty acids (e.g., palmitoyl acid, stearic acid, oleic acid) (Table 1) $[20,95,98-102]$. By varying the degree of substitution of the hydrophobic moiety, it is easy to control the particle size and zeta potentials of the nanoparticles which are important parameters affecting biodistribution of nanoparticles in vivo. As described earlier, chitosan-based SNPs can encapsulate a quantity of hydrophobic drugs inside the nanoparticles. Studies using chitosan nanoparticles have been carried out for various anticancer drugs [25,67,95-97]. In general, the results have demonstrated that chitosan nanoparticles are stable in a physiological solution without signi.cant change in the particle size for a long period of time. The cancer cells ef.ciently take 
them up in vitro because the positively charged surface allows for strong interaction with themembrane of the cancer cells, facilitating endocytosis. When chitosan-based SNPs are systemically administrated into tumor-bearing mice, the nanoparticles are circulated in the bloodstream for at least 1 day, thereby increasing the probability of the nanoparticles reaching the target site [25]. The drug-loaded SNPs could release the biologically active agent in a sustainedmanner, in which the release rate of the drug is dependent on the type of hydrophobic moiety, its degree of substitution, and the physicochemical properties of the drugs. It should be emphasized that a signi.cant amount of chitosan-based SNPs have been reported to be selectively accumulated into the tumor site, primarily owing to the EPR effect $[96,97]$. As a consequence, drug-loaded nanoparticles have shown better therapeutic ef.cacy in vivo than the free drug. A few examples of SNPs for drug delivery, published in recent years, are as follows.

Kwon et al. developed hydrophob cally di.ed glycol chitosans (HGCs) by coyalent njug on of bile acid (5â-cholanic acid or deoxyc ic to the backbone of glycol h san using c odiin chemistry [20,103]. hey o trolled the gree of substitution, deneatas the nu ber of bile rds per 100 sugar its, by varying the ed ratio of the bile acid to gly chi osan. The an philicity, which jo th ydrop ric-hydrophilic balance, was shown o gre $y$ in.u char -teristics of nanoparticles ch their siz pota potential, and morphology. I he at us state, SNPs were stable in biological co tions or at least 1 week. The critical agg tion concentration of HGCs was lower than those of low molecular weight surfactants. Animal experiments showed that HGCs prolonged blood circulation and exhibited high tumor speci.city for delivery of diverse anticancer drugs such as doxorubicin, paclitaxel, docetaxel, camptothecin and cisplatin [25, 67, 95-97].

Zhang et al. synthesized a series of chitosan derivatives carrying long alkyl chains $(n=8,10,12)$ as hydrophobicmoieties and sulfated groups as hydrophilic moieties [104,105]. Alkylation was performed at the C-2 position and sulfonylation at the C- 6 position of the chitosan. The resulting chitosan amphiphiles exhibited no intravenous stimulation, injection anaphylaxis, hemolysis, and cytotoxicity [106]. The authors suggested that the alkylated sulfate chitosans possessed a promising potential as the carrier of PTX. Wang et al. synthesized a cholesterol- modi.ed chitosan conjugatewith a succinyl linkage [107]. The potential of the conjugate as a drug carrier was evaluated using epirubicin. The drug loading capacity of the nanoparticles was found to be 7.97$14.0 \%$. The drug was slowly released in vitrom an phosphate-buffered saline (PBS, pH 7.4 ywwich the total amount of the drug release-was - $9 \%$ in $48 \mathrm{~h}$. You et al. synthesized stearate afted chitosan oligosaccharide (C. A) by reactin the carboxyl group of steave ayid hy amine $g$, n of chitosan [108] SA exhibit a glycoli id rke structure bec ase the forma n of/nultiple hydrophob- nicrodo ins near th arface of the nano articles. This ecial spatial structure faci ated the effectiv internalization of the nan articles within the cancer cells (A549 cells). In a tion, PTX-loaded nanoparticles were able to effect iv deliver the drug into the cytoplasmof ancer cens. Thiswas due to protonation of the a e group of chitosan under acidic intracellular conditions, which exerts electrostatic repulsion between the molecules of the nanoparticle and increases the particle size. Recently, the authors also demonstrated that CSSA nanoparticles can effectively deliver doxorubicin into the nuclei of cancer cells [109,110].

Recently, carboxymethyl chitosan has been modi.ed with linoleic acid and evaluated as carrier for adriamycin [111]. The SNPs released adriamycin in a sustained manner, in which the drug-release rate was dependent on the linoleic acid degree of substitution on hydrophilic carboxymethyl chitosan. The in vitro antitumor activity of the drugloaded nanoparticles against HeLa cells was comparable to that of free adriamycin. Zhao et al. synthesized linoleic acid and poly(â-malic acid) double grafted chitosan (LMC) derivatives, which could selfassemble in the aqueous condition with a particle size of 190-350 $\mathrm{nm}$ [112]. The surface charge of the particles was negative in the physiological $\mathrm{pH}$ due to the presence of the ionized carboxyl groups of the poly(â-malic acid). PTX-loaded LMC nanoparticles exhibited signi.cant tumor inhibition ef.cacy relative to that of PTX in Sarcoma 180-bearing mice. Hemolysis and acute toxicity assessment indicated that the LMC nanoparticles could be safe drug carriers for intravenous administration. 


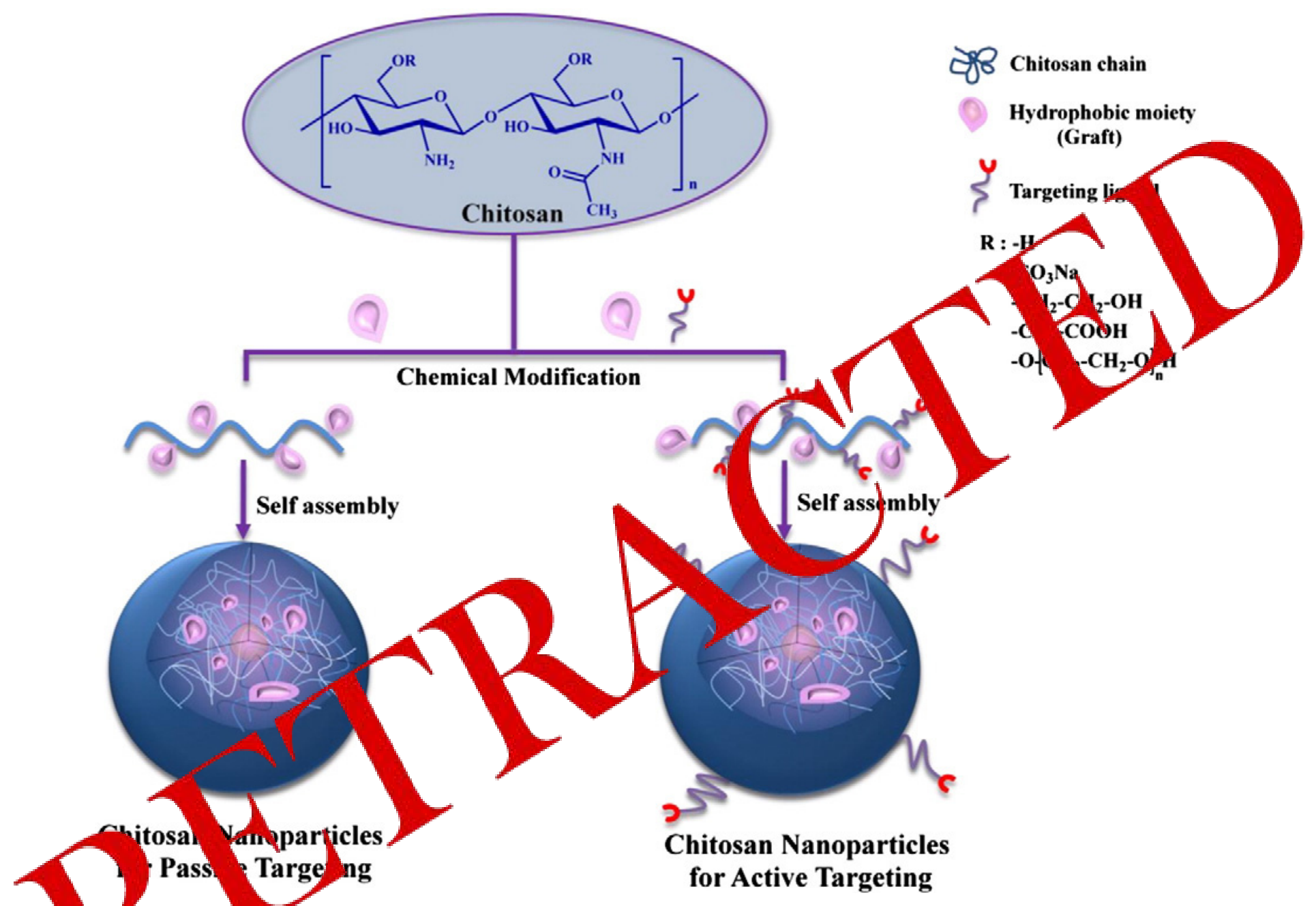

Figure 3. Self-assembled chitosan nanoparticles for passive or active cancer targeting.

PEGylated chitosan nanoparticles

Engineering the surface of the chitosan nanoparticles with PEG has attracted increasing attention because of its great potential in the therapeutic applications [113]. There are numerous publications that reviewed the importance and advantages of PEGylated nanoparticles for biological and pharmaceutical applications $[114,115]$. PEGylation of chitosan nanoparticles can increase their physical stability and prolong their circulation time in blood by reducing the removal by the reticuloendothelial system [113]. In addition, modi.cation of chitosan with PEG can decrease the positive charge of the particle surface.

PEGylated chitosan nanoparticles have been investigated as carriers for diverse small molecular drugs such as paclitaxel, camptothecin, methotrexate, and all-trans retinoic acid (ATRA) [116-120]. Recently, the effect of PEG conjugation on PTX-loaded N-octyl-sulfate chitosan nanoparticles was investigated by $\mathrm{Qu}$ et al. [116]. They found that PEG conjugated particles were phagocytized less than unconjugated nanoparticles by the reticuloendothelial system. The area under the curve of PEG-conjugated nanoparticles was much higher than the unconjugated one. All-trans retinoic acid (ATRA), a compound from retinoid class, is an effective drug for the treatment of epithelial and hematological malignancies but it can readily undergo degradation when exposed to light. This could be surmounted by incorporation of ATRA into N-phthalolylchitosan-g-mPEG (PLC-g- 
mPEG) nanoparticles [117]. The photostability of ATRA in the nanoparticle was signi.cantly improved, when compared to ATRA in ethanol solution. Recently, Jeong et al. found that ATRA can be effectively incorporated into the methoxy poly(ethylene glycol)-grafted chitosan nanoparticles through ionic complexation [118].

\section{Active targeting - receptor-mediated endocytosis (RME)}

The accumulation of drugs in tumor tissue does not always guarantee successful therapy if the drug does not reach the target site of the tumor cell such as the cell membrane, cytosol, or nucleus. Therefore, a more effective mechanism should be employed such that the therapeutic agents are able to reach their molecular targets. Cancer cells often over-express some specific antigens or receptors on their surfaces, which can be utilized as rets in modern nanomedicine. Active tar ting a be achieved by chemical alteration of $n$ size / drug carriers with targeting components th pu vly recognize and specificolly ract with $r$ ptors the targeted tissue [ $21-1$. In its ea stage, researchers attempted direct onjugatioy of the targeting a ety to drugs. Ho ver, most clinical studies con ted for targeted arug conjugates farle, den strate th ir improved therapeutic fects on can treatyent. This was due to a re in the rogical activity of the drugs, co prom by conjugation of the targeting mo y. In addition, conjugation negatively affected the $t$ oeting molecule by disrupting receptor/ligand recognition [124]. To circumvent this problem, researchers developed an efficient drug delivery system comprised of (a) active chemotherapeutic drug, (b) targeting moiety, and (c) a nano-sized carrier made up of polymers or lipids. In this system, the therapeutic agents are physically entrapped in the carrier. This ternary system is very attractive over the ligand- drug conjugates for the following reasons: (i) the physically entrapped drugs can preserve its activity, (ii) a relatively large payload of drugs can be loaded into the hydrophobic cores of the carriers exceeding their intrinsic water solubility, (iii) the targeting moieties on the surface of the carriers can be precisely tuned to increase the probability of binding to the target cells, and (iv) owing to the small size of the carrier system, it can effectively infiltrate across the inflamed leaky disease vasculature but not at the normal vasculature [122]. For successful active targeting, the specific receptors should be expressed exclusively on the cancer cells but not on the normal cells. Several targeting moieties or ligands have been identified and successfully utilized for chitosan-based drug delivery systems.

Folic acid, a low molecular wht ( $1 \mathrm{Da})$ vitamin, has a high affinity for folate re tors (FRs), which are frequently or explessed in ny types of human cancerous cell parucularly th found in the epith al tumors various prgans such as colon, ung, $\mathrm{p}$ state and o ies. Therefore, folate-conjus ted drug or carriers an be rapidly inter alized into cancer $11 \mathrm{~s}$ via receptor-mediated end ytosis. You et synthesized folatecon ated stoaric acid-grafted chitosan oligo charides (Fa-CSOSA) by reacting CSOSA with 1 acid in the presence of carbodiimide upling agents [125]. The cellular uptake of FaC. A nanoparticles bearing PTX $(4.8 \%(\mathrm{w} / \mathrm{w}))$ vid receptor-mediated endocytosis was tested. The authors demonstrated that HeLa cells expressing a large amount of FRs on the cell membrane rapidly took up the Fa-CSOSA nanoparticles, in comparison to A549 cells, an FR-de.cient cell line. Transferrin (Tf), an $80-\mathrm{kDa}$ glycoprotein, is found abundantly in the blood. The main function of $\mathrm{Tf}$ is to transport iron to cells with the transferrin receptors (TfRs). Since TfRs are over-expressed in malignant tissues, Tf can be used as a ligand for tumor targeting. It has been con.rmed that Tfmediated drug delivery systems can overcome drug resistance because they can be internalized by avoiding the membrane-associated drug resistance proteins such as p-glycoprotein [126]. Dufes et al. prepared Tf-decorated palmitoylated glycol chitosan (GCP) nanoparticles which encapsulated a quantity of DOX [24]. The results showed that A431 cells effectively assimilated the Tf-GCP nanoparticles in comparison to the nontargeted nanoparticles. All nanoparticular formulations using GCP showed a superior in vivo safety pro.le, compared to the free drug. As described earlier, a chemical compound containing the galactose moiety can be recognized speci.cally by the asialoglycoprotein receptors found in liver parenchymal cells. Therefore, galactosylated chitosan provides an opportunity for the development of imaging agents and drug carriers for liver-related diseases [127]. 
Ping et al. prepared galactosylated chitosancoated BSA nanoparticles containing 5-FU for the treatment of liver cancer [128]. In this study, 5-FU was physically encapsulated into BSA nanoparticles, followed by surface coating with Ngalactosylated chitosan by electrostatic interactions. Compared to the uncoated nanoparticles, coated nanoparticles showed a sustained release of 5-FU without the signi.cant initial burst in vitro. In general, successful and active drug targeting depends on various parameters, such as the choice of targeting ligands, the conjugation method of the ligands to carriers, and the ligand density on the carrier surface. For example, coupling of ligand to carrier can entrap ligands in the particle interior, which may not be available for receptor-binding $[122,129]$. The reactive amino group of chitosan allows the facile conjugation of the targeting moieties. The schematic illustration for syntheses of FA-conjugated and galactosylated chitosans is shown in Fig. 4. The carboxylic acid of the folic acid has often been reacted with the amino group or the chitosan and its derivatives in the $p$ ence of [1-ethyl-3- (dimethylamino)prepylcarb iimide hydrochloride (EDC) [125] The galacto lated chitosan was synthesized by $t_{1}$ reaction of $\mathrm{ch}$ san with lactobionic arid in the resence of 1 dicyclohexylcarboc nide (DCC and $\mathrm{N}$, N,N'tetramethylet ylened nine (TEM ) [128].

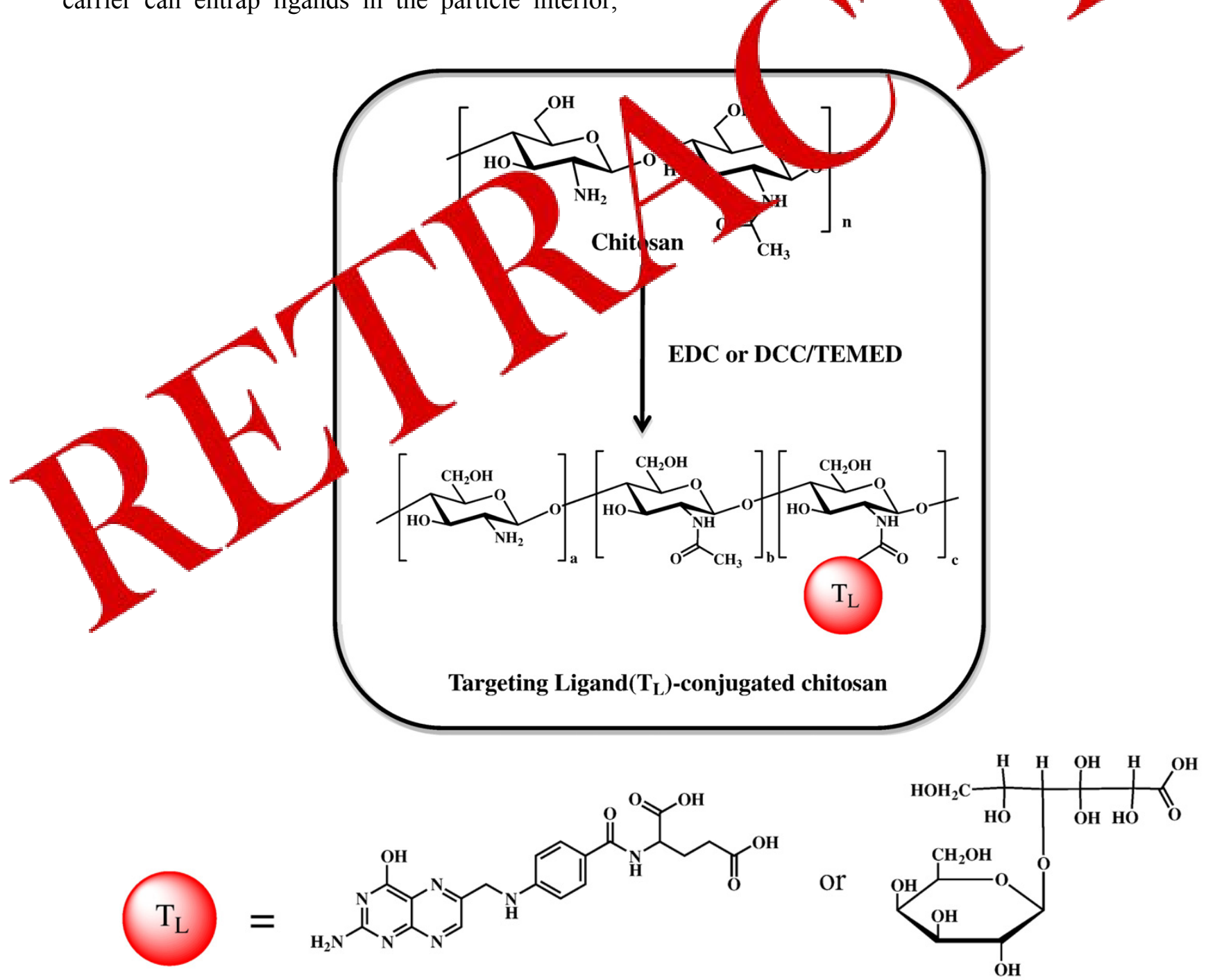

Folic acid

Lactobionic acid

Figure 4. Representative synthetic route for chitosan derivatives containing targeting moieties. 


\section{Physical targeting}

Chitosan-based stimuli-sensitive formulations Increasing efforts have been made to exploit physiological signals such as $\mathrm{pH}$, temperature, ionic strength, and metabolites for targeted drug delivery applications [130-133]. Of the various stimuli, $\mathrm{pH}$ and temperature have been widely investigated for the treatment of solid tumors.Numerous reports havedemonstrated that in.amed or neoplastic tissues could exhibit a lower $\mathrm{pH}$ value (acidosis) or a higher temperature (hyperthermia) than healthy tissue $[131,132]$. Therefore, drug targeting to solid tumors can be achieved by designing stimulisensitive drug carriers, which disintegrate and release the entrapped drugs in response to a lower $\mathrm{pH}$ or higher temperature speci.cally at the tumor site. The interstitial $\mathrm{pH}$ of the tumor plays a prominent role in cancer therapy. In a healthy human, the extracellular $\mathrm{pH}$ of the body tissue and blood is maintained around 7.4. In contrast, the tumor tissue exhibits substantially lower $\mathrm{pH}$ values varying from5.7 to 7.8, depending on tumor histology and volume $[134,135]$. dec ase in extracellular $\mathrm{pH}$ values in tha tu $\mathrm{r}$ rue is primarily due to vasculature in the umol resulting is lowblood pressure, localiry oxia, and cumulatio racidic metabolit This difference $\mathrm{pH}$ between tumors and norma ssue has stimulate any investigators ign no ph-sensitive carriers [136,137]. For Yas et al. repared a camptothecinpoly(N-isopropylacrylamide) Am) chitosan nanoparticle and
potential as a $\mathrm{pH}$-sensitive carrier in tur targeting [138]. The nanoparticles encapsulated $8.4 \%$ of the drug with a loading ef.ciency of $73.7 \%$. The in vitro cytotoxicity of the drug-loaded nanoparticles was compared with free camptothecin against SW480 cells at $\mathrm{pH}$ values of 6.8 and 7.4. The drug-loaded nanoparticles significantly enhanced cytotoxicity at $\mathrm{pH} 6.8$ but displayed minimal cytotoxicity at $\mathrm{pH}$ 7.4. This distinction was ascribed to $\mathrm{pH}$-sensitive drugrelease behavior of the carrier system. In particular, when the mass ratio between the NIPAAm and chitosan was $4: 1$, the drug-loaded nanoparticles were more sensitive to tumor $\mathrm{pH}$ [138].

For anticancer drugswhose targetmolecules arewithin the cells, the drugs have to penetrate the cellular membrane and escape from the endosome before exhibiting their biological effects. In the case of paclitaxel, whose primary site of action is the microtubule, its intracellular concentration is critical for its pharmacological effect. Therefore, ef.cient intracellular delivery of such drugs is essential to eradicate cancer cells. Recently, Nacetyl histidine conjugated glycol chitosan (NAcHis-GC), where histidine (with imidum group, $\mathrm{pKa}$ value of 6.5) acts as $\mathrm{pH}$ sponsive fusogen, was developed for the ef.cient intracytoplasmic delivery of paclitaxe [139]. TheNAcHis-GC conjugate rmed self-ass bled nanoparticles, with ma di ete of $150 \quad 250$ $\mathrm{nm}$, at neutral $\mathrm{pH}$ ue to the $\mathrm{h}$ ophobic aty of the NAcHis oup Jowever, u r sligh y acidic condition ( imilar endosom theimidazole grou ofNAtHis gets rotonated Thismay induce the in.ux of water and ns into endosomes when th hanoparticles are tal on up by the cells, causing dis tion of endosomal membranes (Fig. 5). As a cons ence, the disassembled nanoparticles could release numcapsulated paclitaxel into the cytosol.

Kumacheva et al. prepared $\mathrm{pH}$-responsive c. nosan-based microgels ( $<200 \mathrm{~nm}$ diameter $)$ by ionically cross-linking N-[(2-hydroxy- 3trimethylammonium)propyl]chitosan chloride in the presence of tripolyphosphate [140]. These microgels were loaded with methotrexate and conjugated to apo-transferrin. The authors demonstrated that the conjugated microgels exhibited a signi.cant increase in cell mortality of HeLa cells, compared to non-conjugated microgels. This was ascribed not only to receptor-mediated endocytosis of the conjugated microgels, but also to $\mathrm{pH}$-mediated release of methotrexate from the microgels by their swelling at the intracellular level.

\section{Chitosan-based magnetic nanoparticles}

Magnetic targeting, an attractive physical targeting technique, is garnering substantial attention for drug delivery applications. Here, the therapeutic agents to be delivered are either immobilized on the surface or encapsulated into the magnetic micro- or nanoparticulate carriers. These magnetic carriers, upon intravenous administration, concentrate at the specificsite of interest (tumor site) using an external high-gradient magnetic .eld (Fig. 6) [141]. After accumulation of the magnetic carrier at the target tumor site in vivo, drugs are released from the magnetic carrier and effectively taken up by the tumor cells. 


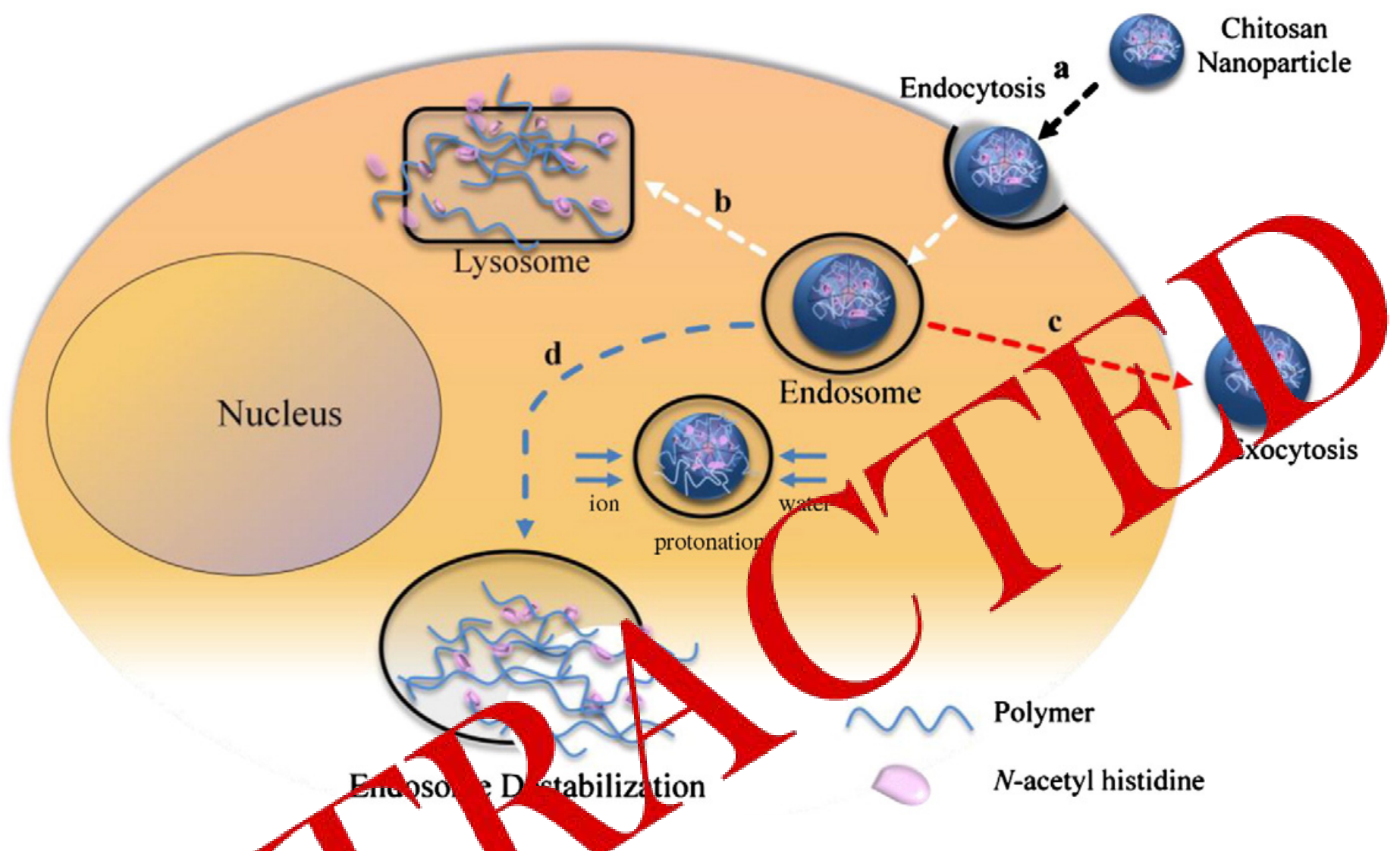

Figure 5. Schematic re resent of a prop d model for the cellular internalization and drug release of NAcHis-GC nanoparticles. (a) Atemalizati of $\mathrm{NAcH}, \mathrm{GC}$ nanoparticles is initiated by nonspecific interactions between nanoparticle and cell membrane (b) A part of the nanoparticles is exocytosed. (c)Without a specific mechanism for endosomal e pe, lrug-loaded na orticles are trafficked to lysosomes, where a high level of lysosomal enzymes is pre-Drugs sitme to these ep Lymes are degraded and lose their activity. (d) Under slightly acidic environments in ndose s, the nidazole roup of histidine is protonated, causing the disruption of endosomal membranes and multa cous deli vof drags into the cytosol. Modified with permission from Ref. [64].

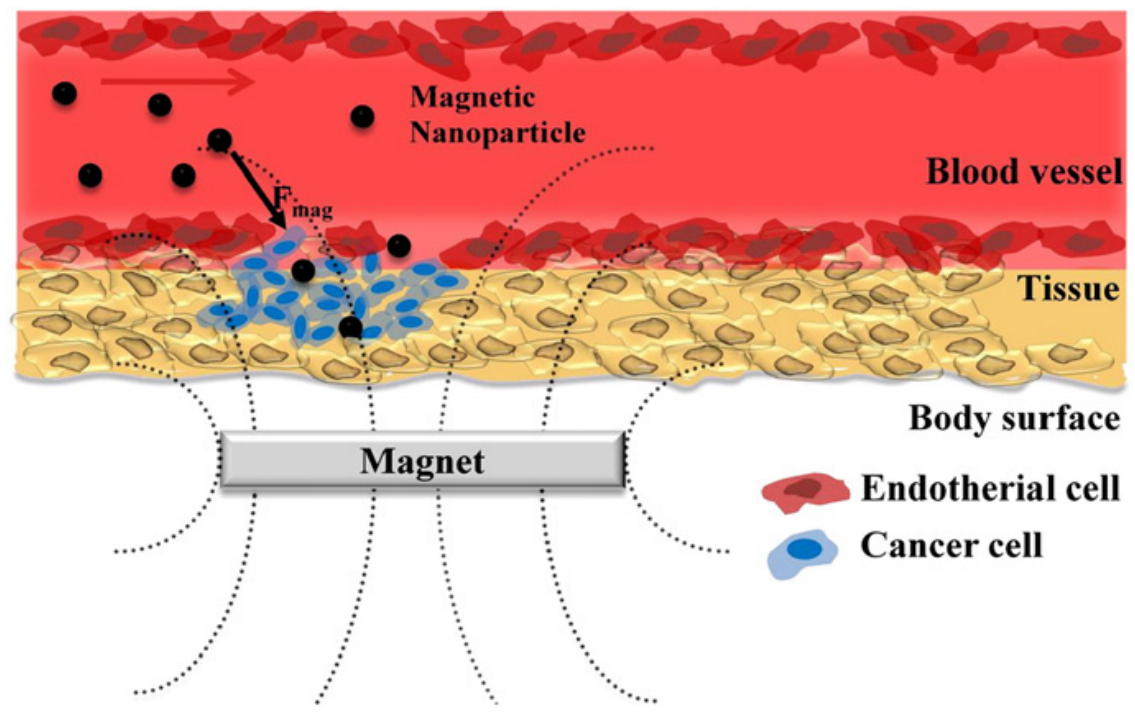

Figure 6. Schematic representation of magnetic nanoparticle-based drug delivery system. 
The ef.ciency of the carrier accumulation depends on various parameters that include intensity of the magnetic .eld, rate of blood .ow, and surface characteristics of carriers.

Targeted delivery of therapeutic agents to the brain has enormous potential for the treatment of several neurological disorders such as Alzheimer's disease and brain tumor. However, the blood-brain barrier (BBB) signi.cantly impedes the entry of drug molecules into the brain from the bloodstream. Drug-loaded magnetic particulates represent a promising alternative strategy in overcoming the BBB. Gallo et al. developed magnetic chitosan microspheres containing oxantrazole (MCM-OX), an anticancer drug, for the treatment of brain tumors [142]. The authors monitored the levels of $\mathrm{OX}$ in the brain after administering intraarterial injections of MCM-OX to male Fischer 344 rats under a magnetic .eld of $6000 \mathrm{G}$ for $30 \mathrm{~min}$. Compared to OX in solution, there was at least a 100 fold increase in OX concentrations in the brain after administration of MCM-OX. Interestingly, even in the absence of an external magnetic .eld, the OX concentrations were similar at 120 mim 30 min after MCM-OX treatment. This attri ted to the cationic-anionic interaction on $\mathrm{MCN}-\mathrm{OX}$ with the blood brain barrier Tore recent She al. developed nanoparticles contoning 5-Fu (CS-5-FU VPs) through a reverse microemuls method, as a potential drus elivery system [1 The resulting nanoparticles as their drug in a sustained manner der in tro cond jons. The FITC-labeled c 5-FU MNPs ectively gained entry into the St at cel and induced cell apoptosis. In a sil ar stu Chen et al. prepared chitosanboun magnetic nanoparticles loaded with epirub $n$, an anthracyline drug used for cancer chemotherapy [144]. The magnetic nanoparticles were stable at $\mathrm{pH} 3-7$, and approximately $80 \%$ of the drug was released after $150-300 \mathrm{~min}$ in a biological buffer. The in vitro anticancer ef.cacy of the drug-loaded magnetic nanoparticles was comparable to that of the free drug. Misra et al. encapsulated doxorubicin-conjugated magnetite nanoparticles into a thermosensitive polymer, chitosan-g-poly(N-isopropylacrylamideco- $\quad \mathrm{N}, \mathrm{N}-$ dimethylacrylamide) [145]. The thermosensitive polymer exhibited a low critical solution temperature of $\sim 38^{\circ} \mathrm{C}$. Since doxorubicin was conjugated to the magnetite via acid-labile hydroazone- bond, the nanoparticles released the drugs in response to a change in external temperature or $\mathrm{pH}$. This particular system is expected to have potential applications in magnetic field-assisted drug delivery.

\section{CONCLUSIONS}

Targeted delivery of drugs is critical in improvino therapeutic efficacy and minimizing side effects. Since Paul Ehrlich suggested the conee $\mathrm{k}_{\mathrm{k}}$ of a "magic bullet", many research setutists ave attempted to develop drugs that electively de by disease cells but are not harmt to Healthy ce Many approaches are errently a lab to deliv the drugs to the pec c site of a on. The lrug conjugate can $b$ desig d by coval $1_{v}$ ataching the targenting diety to e drug. Cnerwise, the drug $\mathrm{c} h$ be physically eno sulated into nano-sized partic that have the abilit or reach the target site. It is a possible to design prodrugs that are not biolog $1 \mathrm{y}$ active until they meet the target olecules development of such targeted a. ery systems, chitosan and its derivatives poss various advantages such as biocompatibility, biodegradability, mucoadhesivity, and other unique biological properties. Over the last decade, increasing attention has been paid to the development of systems to deliver drugs for long periods at controlled rates. Some of these systems can deliver drugs continuously for over one year. However, little effort has been given to developing systems for the controlled release of nucleic acids. Recently, a novel gene transfer method which allows prolonged release and expression of plasmid DNA in vivo in normal adult animals was established. In this system, a biocompatible natural polymer such as collagen or its derivatives acts as the carrier for the delivery of DNA vectors. The biomaterial carrying the plasmid DNA was administered into animals and, once introduced, gradually released plasmid DNA in vivo. A single injection of plasmid DNA biomaterial produced physiologically significant levels of gene-encoding proteins in the local and systemic circulation of animals and resulted in prolonged biological effects. These results suggest that the biomaterials carrying plasmid DNA may enhance the clinical potency of plasmid-based gene transfer, facilitating a more effective and long-term use of naked plasmid vectors for gene therapy. Furthermore, the 
biomaterials can be removed surgically, minimizing the effect of gene products if some unexpected side effects should be observed after application. The application of these systems to expand the bioavailability of molecular medicine, including antisense oligonucleotides and adenovirus vectors, and to aid in stem cell transplantation in the context of DNA-based tissue engineering will be discussed. Chitosan has been the subject of interest for its use as a polymeric drug carrier material in dosage form design due to its appealing properties such as biocompatibility, biodegradability, low toxicity and relatively low production cost from abundant natural sources. However, one drawback of using this natural polysaccharide in modified release dosage forms for oral administration is its fast dissolution rate in the stomach. Since chitosan is positively charged at low $\mathrm{pH}$ values (below its $\mathrm{pK}_{\mathrm{a}}$ value), it spontaneously associates with negatively charged polyions in solution to form polyelectrolyte complexes. These chitosan based polyelectrolyte complexes exhibit favourable phy hemical properties with preservation if c osan's biocompatible characteristics hese $\mathrm{mp}$ xes are therefore good candidate xcipient ma rals the design of different to pes dosage for It is ve aim of this revew to de ribe comp tion of chitosan with selected $\mathrm{n}$ ral and synthetic polyanior and to indicate sor of the factors that influence mation and stability of these poly ctroly comple es. Furthermore, recent inves gations to the use of these complexes as to in di delivery systems such as nanoa miv articles, beads, fibers, sponges and $m$ ix type tablets are briefly described. The pro rties of chitosan are greatly influenced by its molecular weight and degree of deacetylation. The presence of reactive functional groups in chitosan provides great opportunity for chemical modification, which affords a wide range of derivatives possessing unique properties. Overall, it is evident that chitosan and its derivatives are useful carriers for low molecular drugs requiring targeted delivery. The scope of polymers used in dosage form design can be increased by several approaches such as modification of their chemical structure, by combining different polymers in physical mixtures or by formation of polymer-polymer associations such as polyelectrolyte complexes. Polyelectrolyte complexes combine unique physicochemical properties of different polymers with the advantage of retaining high biocompatibility. It is therefore not surprising that polyelectrolyte complexes are gaining importance in modern pharmaceutical technology. From the in vitro studies conducted on chitosan-based polyelectrolyte complexes it is clear that they are valuable excipients with specific properties for efficient dosage form design, which may be valuable in the development of nodifia drug delivery systems. Unfortunately, it iterature lacks in vivo data in terms of drand delit $\mathrm{y}$ from these dosage forms which makes it difficu to be conclusive in terms of heln fectiveness a trug carriers at this stage. Since s ne pork has en done on in ov -in vivo orrelatio with chemically, ross-li ed chitosa hydyogels with successtur ustained g delivery animals, it is ant ipated that on mized chitosan based po electrolyte complex may also perform up to ex ctation for ih vivo arug delivery.

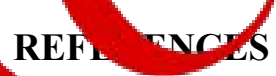

A. DiMasi, R.W. Hansen, H.G. Grabowski, The price of innovation: new estimates of drug development costs, J. Health Econ. 22 (2003) 151185.

2. R. Langer, Drug delivery and targeting, Nature 392 (1998) 5-10.

3. G. Poste, R. Kirsh, Site-specific(targeted) drug delivery in cancer therapy, Biotechnology 1 (1983) 869-878.

4. G. Gregoriadis, Targeting of drugs, Nature 265 (1977) 407-411.

5. K. Strebhardt, A. Ullrich, Paul Ehrlich's magic bullet concept: 100 years of progress, Nat. Rev. Cancer 8 (2008) 473-480.

6. J.K. Vasir, M.K. Reddy, V.D. Labhasetwar, Nanosystems in drug targeting: opportunities and challenges, Curr. Nanosci. 1 (2005) 47-64.

7. R. Duncan, The dawning era of polymer therapeutics, Nat. Rev. Drug Discov. 2 (2003) 347360.

8. R. Duncan, Polymer conjugates for drug targeting. Frominspired to inspiration! J.Drug Target 14 (2006) 333-335.

9. V. Torchilin, Antibody-modi.ed liposomes for cancer chemotherapy, Expert Opin Drug Deliv 5 (2008) 1003-1025.

10. S.G. Sampathkumar, K.J. Yarema, Targeting cancer cells with dendrimers, Chem. Biol. 12 (2005) 5-6.

11. Z. Liu, Y. Jiao, Y. Wang, C. Zhou, Z. Zhang, Polysaccharides-based nanoparticles as drug delivery systems, Adv. Drug Deliv. Rev. 60 (2008) 1650-1662. 
12. M.N. Kumar, R.A. Muzzarelli, C. Muzzarelli, H. Sashiwa, A.J. Domb, Chitosan chemistry and pharmaceutical perspectives, Chem. Rev. 104 (2004) 6017-6084.

13. L. Illum, Chitosan and its use as a pharmaceutical excipient, Pharm. Res. 15 (1998) 1326-1331.

14. O. Felt, P. Buri, R. Gurny, Chitosan: a unique polysaccharide for drug delivery, Drug. Dev. Ind. Pharm. 24 (1998) 979-993.

15. A. Bernkop-Schnurch, D. Guggi, Y. Pinter, Thiolated chitosans: development and in vitro evaluation of a mucoadhesive, permeation enhancing oral drug delivery system, J. Control Release 94 (2004) 177-186.

16. M. Amidi, S.G. Romeijn, G. Borchard, H.E. Junginger, W.E. Hennink, W. Jiskoot, Preparation and characterization of protein-loaded N-trimethyl chitosan nanoparticles as nasal delivery system, J. Control Release 111 (2006) 107-116.

17. Y. Wang, Q. Jiang, R. Li, L. Liu Q. nng, Y. Wang, J. Zhao, Self-assembled nopar les of cholesterol-modi.ed $\mathrm{O}$ carbon, neth chite an as a novel carrier for pacl axel, Nano moly 19 (2008) 145101.

18. J.H. Park, Y.W. ho, H. hung, I.C. I on, S.Y. Jeong, Synthesis and ch cterization or sugarbearin hitosan derivatives. ueous solubility and biodegr bilit, Biomacron fules 4 (2003)

19. A rapani, G. Fuen s, M.J. Alonso, Novel drug n ocarriers ambining hydrophilic cyclodextrins aitosan, anotechnology 19 (2008) 185101.

2 K. K. CKwon, J.H. Park, H. Chung, S.Y. Jeong, C. Kwon, I.S. Kim, Physicochemical aracterizations of self-assembled nanoparticles of glycol chitosan-deoxycholic acid conjugates, Biomacromolecules 6 (2005) 1154-1158.

21. K. Kurita, Chitin and chitosan: functional biopolymers from marine crustaceans, Mar. Biotechnol. (NY) 8 (2006) 203-226.

22. V.K. Mourya, N.N. Inamdar, Chitosan-modi.cations and applications: opportunities galore, React. Funct. Polym. 68 (2008) 1013-1051.

23. V.M. Leitner, G.F. Walker, A. Bernkop-Schnurch, Thiolated polymers: evidence for the formation of disulphide bonds with mucus glycoproteins, Eur. J. Pharm. Biopharm. 56 (2003) 207-214.

24. C. Dufes, J.M. Muller, W. Couet, J.C. Olivier, I.F. Uchegbu, A.G. Schatzlein, Anticancer drug delivery with transferrin targeted polymeric chitosan vesicles, Pharm. Res. 21 (2004) 101-107.

25. J.H.Kim,Y.S.Kim,K. Park, S. Lee,H.Y.Nam,K.H.Min,H.G. Jo, J.H. Park,K.Choi, S.Y. Jeong, R.W. Park, I.S. Kim, K. Kim, I.C. Kwon, Antitumor ef.cacy of cisplatin-loaded glycol chitosan nanoparticles in tumor-bearing mice, J. Control Release 127 (2008) 41-49.

26. H.S. Yoo, J.E. Lee, H. Chung, I.C. Kwon, S.Y. Jeong, Self-assembled nanoparticles hydrophobically modi.ed glycol chito for gene delivery, J. Control Release 103 (2005) 23 243.

27. J.P. Overington, B. Al-Lazikani, A.L.Hopk How many drug targets are ther Nat. Rev. Drug scov. 5 (2006) 993-996.

28. M.K. Chourasia S.K. Jain, olysacchatide colon targeted a delivery, D Deliv. (2004) 129-148.

29. S.K. Jan A. Jain, get-specific ag release to the olon, Expert. Opin. ug Deliv. 5 (2008) 483-498.

30. R. Hejazi, M. Amiji, C osan-based gastrointestinal elivery systems, J. Control Release 89 (2003) 1515.

31. Tozaki, J Komoike, C. Tada, T. Maruyama, A. Teran Suzuki, A. Yamamoto, S. Muranishi, Chitosan capsules for colon-specificdrug delivery: mprovement of insulin absorption from the rat colon, J. Pharm. Sci. 86 (1997) 1016-1021.

32. H. Tozaki, T. Odoriba, N. Okada, T. Fujita, A. Terabe, T. Suzuki, S. Okabe, S. Muranishi, A. Yamamoto, Chitosan capsules for colonspecificdrug delivery: enhanced localization of 5aminosalicylic acid in the large intestine accelerates healing of TNBS-induced colitis in rats, J. Control Release 82 (2002) 51-61.

33. G. Fetih, S. Lindberg, K. Itoh, N. Okada, T. Fujita, F. Habib, P. Artersson, M. Attia, A. Yamamoto, Improvement of absorption enhancing effects of ndodecyl-beta-Dmaltopyranoside by its colonspecificdelivery using chitosan capsules, Int. J. Pharm. 293 (2005) 127-135.

34. J. Varshosaz, A. Jaffarian Dehkordi, S. Golafshan, Colon-specificdelivery of mesalazine chitosan microspheres, J. Microencapsul. 23 (2006) 329-339.

35. K. Mladenovska, R.S. Raicki, E.I. Janevik, T. Ristoski, M.J. Pavlova, Z. Kavrakovski, M.G. Dodov, K. Goracinova, Colon-specificdelivery of 5aminosalicylic acid from chitosan-Ca-alginate microparticles, Int. J. Pharm. 342 (2007) 124-136.

36. S.K. Jain, A. Jain, Y. Gupta, A. Jain, P. Khare, M. Kannandasan, Targeted delivery of 5-ASA to colon using chitosan hydrogel microspheres, J. Drug Deliv. Sci. Tech. 18 (2008) 315-321.

37. M.L. Lorenzo-Lamosa, C. Remunan-Lopez, J.L. Vila-Jato, M.J. Alonso, Design of microencapsulated chitosan microspheres for colonic drug delivery, J. Control Release 52 (1998) 109-118.

38. T. Oosegi, H. Onishi, Y. Machida, Novel preparation of enteric-coated chitosan- prednisolone conjugate microspheres and in vitro evaluation of 
their potential as a colonic delivery system, Eur. J. Pharm. Biopharm. 68 (2008) 260-266.

39. S.K. Jain, A. Jain, Y. Gupta, M. Ahirwar, Design and development of hydrogel beads for targeted drug delivery to the colon, AAPS PharmSciTech 8 (2007) E56.

40. M.K. Chourasia, S.K. Jain, Design and development of multiparticulate system for targeted drug delivery to colon, Drug Deliv. 11 (2004) 201-207.

41. A.A. Elzatahry, M.S.M. Eldin, Preparation and characterization of metronidazole loaded chitosan nanoparticles for drug delivery application, Polym. Adv. Technol. 19 (2008) 1787-1791.

42. A. Jain, S.K. Jain, In vitro and cell uptake studies for targeting of ligand anchored nanoparticles for colon tumors, Eur. J. Pharm. Sci. 35 (2008) 404-416.

43. K. Ogawara, M. Yoshida, K. Higaki, T. Kimura, K Shiraishi, M. Nishikawa, Y. Takakura, M Hashida, Hepatic uptake of polystyrene microsphe in rats: effect of particle size on intrahepa distri tion, J. Control Release 59 (1999)

44. Y. Kato, H. Onish Y. Machic characteristics chitosan as liver-spec drug carrie mice, J. Control Release 70 (2001) $\quad-307$.

45. Y. H H, Onishi, Y. achida, Ef.cacy of lactosan ater and intact succinylchitosan tomyc C conju zates against M5076 liver astatic ncer, J. harm. Pharmacol. 54 (2002) 9-537.

K. Yang, R. Li, Z.L. Yang, P.Z. Li, F. Wang, Y. Li wovel polyion complex micelles for liverargeted delivery of diammonium glycyrrhizinate: in vtro and in vivo characterization, J. Biomed. Mater. Res. A. 88 (2009) 140-148.

47. A. Lin, Y. Liu, Y. Huang, J. Sun, Z. Wu, X. Zhang, Q. Ping, Glycyrrhizin surfacemodified chitosan nanoparticles for hepatocyte-targeted delivery, Int. J. Pharm. 359 (2008) 247-253.

48. R. Vriesendorp, A.J. Donker, D. de Zeeuw, P.E. de Jong, G.K. van der Hem, J.R. Brentjens, Effects of nonsteroidal anti-in.ammatory drugs on proteinuria, Am. J. Med. 81 (1986) 84-94.

49. K. Suzuki, H. Susaki, S. Okuno, Y. Sugiyama, Renal drug targeting using a vector, alkylglycoside, J. Pharmacol. Exp. Ther. 288 (1999) 57-64.

50. S. Wilk, H. Mizoguchi, M. Orlowski, Gammaglutamyl dopa: a kidney-speci.c dopamine precursor, J. Pharmacol. Exp. Ther. 206 (1978) 227232.

51. M. Haas, A.C. Kluppel, E.S. Wartna, F. Moolenaar, D.K. Meijer, P.E. de Jong, D. De Zeeuw, Drugtargeting to the kidney: renal delivery and degradation of a naproxen-lysozyme conjugate in vivo, Kidney Int. 52 (1997) 1693-1699.
52. H. Kodaira, Y. Tsutsumi, Y. Yoshioka, H. Kamada, Y. Kaneda, Y. Yamamoto, S. Tsunoda, T. Okamoto, Y. Mukai, H. Shibata, S. Nakagawa, T Mayum The targeting of anionized polyvinyl lidone to the renal system, Biomaterials 5 (20 43094315.

53. H. Onishi, Y. Machi Bigdegradatic and distribution of wans solu cl tosan in ice, Biomaterials 20 1999) 175-

54. Z.X. Yuan X. , T. Gong, Ding, Y Fu, Z.R. Zhang R ndomly $\%$ N-acety dyow molecular yerght c ilosan as ovel renal argeting carrier, J. Drug Target 15 (200 269-278.

55 Z.X. Yuan, Z.R. Zhan Y.Zhu, X. Sun, T. Gong, J. iu, C.T. Luan, Specificrenal uptake of randomly $\%$ N-acety ated low molecular weight chitosan, h. Pharm/6 (2009) 305-314.

56. A. Jural, R. Siegel, E. Ward, Y. Hao, J. Xu, T. Murray, M.J. Thun, Cancer statistics, 2008, CA Cancer J. Clin. 58 (2008) 71-96.

57. H.M. Courrier, N. Butz, T.F. Vandamme, Pulmonary drug delivery systems: recent developments and prospects, Crit. Rev. Ther. Drug Carrier Syst. 19 (2002) 425-498.

58. K. Saralidze, C.S. van Hooy-Corstjens, L.H. Koole, M.L. Knetsch, New acrylic microspheres for arterial embolization: combining radiopacity for precise localization with immobilized thrombin to trigger local blood coagulation, Biomaterials 28 (2007) 2457-2464.

59. D.R. Klonne, D.E. Dodd, P.E. Losco, C.M. Troup, T.R. Tyler, Pulmonary .brosis produced in F-344 rats by subchronic inhalation of aerosols of a 4000 molecular weight ethylene oxide/propylene oxide polymer, Fundam. Appl. Toxicol. 10 (1988) 682690.

60. R. Yang, S.G. Yang, W.S. Shim, F. Cui, G. Cheng, I.W. Kim, D.D. Kim, S.J. Chung, C.K. Shim, Lungspecificdelivery of paclitaxel by chitosan-modi.ed PLGA nanoparticles via transient formation of microaggregates, J. Pharm. Sci. 98 (2009) 970-984.

61. R. Yang, W.S. Shim, F.D. Cui, G. Cheng, X. Han, Q.R. Jin, D.D. Kim, S.J. Chung, C.K. Shim, Enhanced electrostatic interaction between chitosanmodi.ed PLGA nanoparticle and tumor, Int. J. Pharm. 371 (2009) 142-147.

62. V.P. Torchilin, Targeted polymeric micelles for delivery of poorly soluble drugs, Cell. Mol. Life Sci. 61 (2004) 2549-2559.

63. Y. Matsumura, H. Maeda, A new concept for macromolecular therapeutics in cancer chemotherapy: mechanism of tumoritropic accumulation of proteins and the antitumor agent smancs, Cancer Res. 46 (1986) 6387-6392.

64. H. Maeda, The enhanced permeability and retention (EPR) effect in tumor vasculature: the key role of 
tumor-selective macromolecular drug targeting, Adv. Enzyme Regul. 41 (2001) 189-207.

65. H. Ringsdorf, Structure and properties of pharmacologically active polymers, J. Polym. Sci. Polym. Symp. 51 (1975) 135-153.

66. L.W. Seymour, K. Ulbrich, S.R. Wedge, I.C. Hume, J. Strohalm, R. Duncan, N-(2hydroxypropyl)methacrylamide copolymers targeted to the hepatocyte galactosereceptor: pharmacokinetics in DBA2 mice, Br. J. Cancer 63 (1991) 859-866.

67. Y.J. Son, J.S. Jang, Y.W. Cho, H. Chung, R.W. Park, I.C.Kwon, I.S. Kim, J.Y. Park, S.B. Seo, C.R. Park, S.Y. Jeong, Biodistribution and anti-tumor ef.cacy of doxorubicin loaded glycol-chitosan nanoaggregates by EPR effect, J. Control Release 91 (2003) 135-145.

68. E. Lee, J. Lee, I.H. Lee, M. Yu, H. Kim, S.Y. Chae, S. Jon, Conjugated chitosan as a novel platform for oral delivery of paclitaxel, J. Med. Chem. 51 (2008) 6442-6449.

69. Y. Song, H. Onishi, T. Nagai, Synthesis and drug release characteristics of the conjugates mitomycin $\mathrm{C}$ with N-succinyl-chitosan carboxymethyl-chitin, Chem Pharm Bull kyo) 40 (1992) 2822-2825.

70. Y. Kato, H. Onishi, chitosan as a drug car soluble conjugate, Bio terials 25 (26 ) 907-yo.

71. M. Prabahar J. Man Chitosan-ba particles as controlled drug delivery stems, Dy.g Deliv. 12 (2000 $1-57$

72. M. Go erg R. Langer, Jia, Nanostructured aterials $r$ applicat ons in drug delivery and tissue gineerin J. Biom acr. Sci. Polym. Ed. 18 (2007) 41-268.

Nu anar, f. Hartmann, J. Borbely, Preparation and cacterization of chitosan-based nanoparticles, Biomacromolecules 6 (2005) 2521-2527.

74 1. Ohya, M. Shiratani, H. Kobayashi, T. Ouchi, Release behavior of 5-.uorouracil from chitosan-gel nanospheres immobilizing 5-.uorouracil coated with polysaccharides and their cell specificcytotoxicity, Pure Appl. Chem. A31 (1994) 629-642.

75. P. Calvo, C. Remunan-Lopez, J.L. Vila-Jato, M.J. Alonso, Chitosan and chitosan/ ethylene oxidepropylene oxide block copolymer nanoparticles as novel carriers for proteins and vaccines, Pharm. Res. 14 (1997) 1431-1436.

76. S.A. Agnihotri, N.N. Mallikarjuna, T.M. Aminabhavi, Recent advances on chitosanbasedmicro- and nanoparticles in drug delivery, J. Control Release 100 (2004) 5-28.

77. S. Mitra, U. Gaur, P.C. Ghosh, A.N. Maitra, Tumour targeted delivery of encapsulated dextran- doxorubicin conjugate using chitosan nanoparticles as carrier, J. Control Release 74 (2001) 317-323.

78. R. Bodmeier, H.G. Chen, O. Paeratakul, A novel approach to the oral delivery of micro- or nanoparticles, Pharm. Res. 6 (1989) 413-417.

79. K.A. Janes, M.P. Fresneau, A. Marazuela, A. Fabra, M.J. Alonso, Chitosan nanoparticles as delivery systems for doxorubicin, J. Control Release 73 (2001) 255-267.

80. W. Sun, S. Mao, D. Mei, T. Kissel, S assembled polyelectrolyte nanocomplexes etwee chitosan derivatives and enoxapanin, Eur. J. Pharm. Biopharm. 69 (2008)

81. W. Liu, S. Sun, Z, X that, K. Yao, w. Lu, K.D. k, An i stigation on the physicoch nica properties f chi san/DNA polyelact olyte o plexes, Bio arials 26 (2005) 2/05-2,11.

82 A.V. Il'ina, V.P Varlamov, Chitosan-based polyelectrolyte comp ơ: a review, Prikl. Biokhim. Mikrobiol. 41 (2005)9-16.

83. Drogoz, Lavid, C. Rochas, A. Domard, T. ir, Polyelectrolyte complexes from polysaccharides: formation and stoichiometry monitoring, Langmuir 23 (2007) 10950-10958.

A. Denuziere, D. Ferrier, O. Damour, A. Domard, Chitosan-chondroitin sulfate and chitosanhyaluronate polyelectrolyte complexes: biological properties, Biomaterials 19 (1998) 1275-1285.

85. C.L. de Vasconcelos, P.M. Bezerril, D.E. dos Santos, T.N. Dantas, M.R. Pereira, J.L. Fonseca, Effect of molecular weight and ionic strength on the formation of polyelectrolyte complexes based on poly(methacrylic acid) and chitosan, Biomacromolecules 7 (2006) 1245-1252.

86. Y. Hu, X. Jiang, Y. Ding, H. Ge, Y. Yuan, C. Yang, Synthesis and characterization of chitosanpoly(acrylic acid) nanoparticles, Biomaterials 23 (2002) 3193-3201.

87. Y. Zheng, W. Yang, C. Wang, J. Hu, S. Fu, L. Dong, L. Wu, X. Shen, Nanoparticles based on the complex of chitosan and polyaspartic acid sodium salt: preparation, characterization and the use for 5.uorouracil delivery, Eur. J. Pharm. Biopharm. 67 (2007) 621-631.

88. D.Y. Zhang, X.Z. Shen, J.Y. Wang, L. Dong, Y.L. Zheng, L.L. Wu, Preparation of chitosanpolyaspartic acid-5-.uorouracil nanoparticles and its anti-carcinoma effect on tumor growth in nudemice,World J.Gastroenterol. 14 (2008) 35543562.

89. S. Cafaggi, E. Russo, R. Stefani, R. Leardi, G. Caviglioli, B. Parodi, G. Bignardi, D. De Totero, C. Aiello, M. Viale, Preparation and evaluation of nanoparticles made of chitosan or N-trimethyl 
chitosan and a cisplatin-alginate complex, J. Control Release 121 (2007) 110-123.

90. X. Cheng, F. Zhang, G. Zhou, S. Gao, L. Dong, W. Jiang, Z. Ding, J. Chen, J. Zhang, DNA/chitosan nanocomplex as a novel drug carrier for doxorubicin, Drug Deliv. 16 (2009) 135-144.

91. Y. Hu, Y. Ding, D. Ding, M. Sun, L. Zhang, X. Jiang, C. Yang, Hollow chitosan/poly (acrylic acid) nanospheres as drug carriers, Biomacromolecules 8 (2007) 1069-1076.

92. Z. Keresztessy, M. Bodnár, E. Ber, I. Hajdu, M. Zhang, J.F. Hartmann, T. Minko, J. Borbély, Selfassembling chitosan/poly-ã-glutamic acid nanoparticles for targeted drug delivery, Colloid Polym. Sci. 287 (2009) 759-765.

93. R. Gref, Y. Minamitake, M.T. Peracchia, V. Trubetskoy, V. Torchilin, R. Langer, Biodegradable long-circulating polymeric nanospheres, Science 263 (1994) 1600-1603.

94. S.M. Moghimi, A.C. Hunter, J.C. Murray, Longcirculating and target-specific nanoparticles: theory to practice, Pharmacol. Rev. 53 (2001) 283-318.

95. J.H. Kim, Y.S. Kim, S. Kim, J.H. Park, K. Kim, K. Choi, H. Chung, S.Y. Jeong, R.W. Park, I.S. Kim, I.C. Kwon, Hydrophobically modi.ed glycol chitosan nanoparticles as carriers for paclimel, J. Control Release 111 (2006) 228-234.

96. K.H. Min, K. Park, Y.S. Kim, S.M. e, S. Lee, H.G. Jo, R.W. Park, I.S. Kim, S.Y.Jeo K $\eta$, I.C. Kwon, Hydropber lly modi.c glya chitosan nanopartic senca lated cam thecin enhance the drostability a tumor targ $s$ in cancer theropy, J. Control Rele 127 (2008) 208218.

97. H.Y Hwan Ic Kim, I.C. I won, Y.H. Kim, Tu. targ bility an antitumor effect of doce rel-load hydrop iobically modi.ed glycol hite nanop les, J. Control Release 128 $008)$ - 21 .

98. J Zhang, n.G. Chen, Y.Y. Li, C.S. Liu, Selfas bled nanoparticles based on hydrophobically meur.ed chitosan as carriers for doxorubicin, Nanomedicine 3 (2007) 258-265.

99. G.B. Jiang, D. Quan, K. Liao, H. Wang, Novel polymer micelles prepared from chitosan grafted hydrophobic palmitoyl groups for drug delivery, Mol. Pharm. 3 (2006) 152-160.

100.Y.Q. Ye, F.L. Yang, F.Q. Hu, Y.Z. Du, H. Yuan, H.Y. Yu, Core-modi.ed chitosan-based polymeric micelles for controlled release of doxorubicin, Int. J. Pharm. 352 (2008) 294-301.

101.K.Y. Lee, J.-H. Kim, I.C. Kwon, S.Y. Jeong, Selfaggregates of deoxycholic acidmodi .ed chitosan as a novel carrier of adriamycin, Colloid Polym. Sci. 278 (2000) 1216-1219.
102.T. Ngawhirunpat, N. Wonglertnirant, P. Opanasopit, U. Ruktanonchai, R. Yoksan, K. Wasanasuk, S. Chirachanchai, Incorporation methods for cholic acid chitosang- mPEG self-assembly micellar system containing camptothecin, Colloids Surf. B., Biointerfaces 74 (2009) 253-259.

103.S. Kwon, J.H. Park, H. Chung, I.C. Kwon, S.Y. Jeong, Physicochemical characteristics of selfassembled nanoparticles based on glycol chitosan bearing 5bcholanic acid, Langmuir 19 (2002) 10188-10193.

104.C. Zhang, Q. Ping, H. Zhang, J. Shen, Prepa on of $\mathrm{N}$-alkyl-O-sulfate chitosan derivatives and $\mathrm{n}$ llar solubilization of taxol, Carbohvd. Polym. 54 (2 3) 137-141.

105.C. Zhang, P. Qineng H. Zhang elf sembly a characterization paclitaxello ed $\mathrm{N}-\mathrm{oc}$ vlsulfate chitos a mic ar system, c oids S.r. B., Biointerfors $59(200,59-75$.

106.C. Zlang, G. Qu, Y. Su T. Yang, Z Yao, W. Shen, Z. Shen, Q. Ding, H. ou, Q. Ping, Biological ef uation of N-octyl-O- rate chitosan as a new na carrier of ihtravenous drugs, Eur. J. Pharm. Sci (2008) 41;-423.

07. Y.S. no LR. Liu, Q. Jiang, Q.Q. Zhang, Selfiggregated nanoparticles of cholesterol-modi.ed man conjugate as a novel carrier of epirubicin, Lar. Polym. J. 43 (2007) 43-51.

108.J. You, F.Q. Hu, Y.Z. Du, H. Yuan, Polymeric micelles with glycolipid-like structure and multiple hydrophobic domains for mediating molecular target delivery of paclitaxel, Biomacromolecules 8 (2007) 2450-2456.

109.J. You, F.Q. Hu, Y.Z. Du, H. Yuan, Improved cytotoxicity of doxorubicin by enhancing its nuclear delivery mediated via nanosized micelles, Nanotechnology 19 (2008) 255103.

110.F.Q. Hu, X. Wu, Y.Z. Du, J. You, H. Yuan, Cellular uptake and cytotoxicity of shell crosslinked stearic acid-grafted chitosan oligosaccharide micelles encapsulating doxorubicin, Eur. J. Pharm. Biopharm. 69 (2008) 117-125.

111.Y.L. Tan, C.G. Liu, Self-aggregated nanoparticles from linoleic acid modified carboxymethyl chitosan: Synthesis, characterization and application in vitro, Colloids Surf. B., Biointerfaces 69 (2009) 178-182.

112.Z. Zhao, M. He, L. Yin, J. Bao, L. Shi, B. Wang, C. Tang, C. Yin, Biodegradable nanoparticles based on linoleic acid and poly(beta-malic acid) double grafted chitosan derivatives as carriers of anticancer drugs, Biomacromolecules 10 (2009) 565-572.

113.M. Bodnar, J.F. Hartmann, J. Borbely, Synthesis and study of cross-linked chitosan-N-poly(ethylene glycol) nanoparticles, Biomacromolecules 7 (2006) 3030-3036. 
114.H. Otsuka, Y. Nagasaki, K. Kataoka, PEGylated nanoparticles for biological and pharmaceutical applications, Adv. Drug Deliv. Rev. 55 (2003) 403419.

115.J.M. Harris, R.B. Chess, Effect of pegylation on pharmaceuticals, Nat. Rev. Drug Discov. 2 (2003) 214-221.

116.G. Qu, Z. Yao, C. Zhang, X. Wu, Q. Ping, PEG conjugated N-octyl-O-sulfate chitosan micelles for delivery of paclitaxel: in vitro characterization and in vivo evaluation, Eur. J. Pharm. Sci. 37 (2009) 98105.

117.P. Opanasopit, T. Ngawhirunpat, T. Rojanarata, C. Choochottiros, S. Chirachanchai, Nphthaloylchitosan-g-mPEG design for all-trans retinoic acid-loaded polymeric micelles, Eur. J. Pharm. Sci. 30 (2007) 424-431.

118. Y.I. Jeong, S.H. Kim, T.Y. Jung, I.Y. Kim, S.S. Kang, Y.H. Jin, H.H. Ryu, H.S. Sun, S. Jin, K.K. Kim, K.Y. Ahn, S. Jung, Polyion complex micelles composed of all-trans retinoic acid and poly (ethylene glycol)-grafted-chitosan, J. Pharm. Sci. 95 (2006) 2348-2360.

119.P. Opanasopit, T. Ngawhirunpat, A. Chaidedgumjorn, T. Rojanarata, A. Apirakaramwong, S. Phongying, C. Chontiros, $\mathrm{S}$. Chirachanchai, Incorporation of amptc ecin into N-phthaloyl chitosan-g-m ${ }^{\circ E G}$ f-ass mbly micellar system, Eur. J. Pharm. Biophan 64 (6) 269-276.

120.X. Yang, Q. Zhang, . Wan H. Chen, H. ang, F. Gao, L. Liu sorf-agregat nanoparticl Irom methoxy oly(ethylene glyco modi.ed chitosan: synthesis, chalacterization; ropegation and mothotrexa relase in vitro, colloids Surf. B., Bio erfaces (2008) 1 5-131.

J.D. Byrne, Betapeourt, L. Brannon-Peppas, Act targeting cmes for nanoparticle systems in ncer rapeatics, Adv. Drug Deliv. Rev. 60
08) 16r-1626.

122.T Allen, Ligand-targeted therapeutics in anticancer therapy, Nat. Rev. Cancer 2 (2002) 750763.

123.T.H. Kim, H.L. Jiang, J.W. Nah, M.H. Cho, T. Akaike, C.S. Cho, Receptor-mediated gene delivery using chemically modi.ed chitosan, Biomed. Mater. 2 (2007) S95-100.

124.A.W. Tolcher, S. Sugarman, K.A. Gelmon, R. Cohen, M. Saleh, C. Isaacs, L. Young, D. Healey, N. Onetto, W. Slichenmyer, Randomized phase II study of BR96- doxorubicin conjugate in patients with metastatic breast cancer, J. Clin. Oncol. 17 (1999) 478-484.

125.J. You, X. Li, F. Cui, Y.Z. Du, H. Yuan, F. Hu, Folate-conjugated polymer micelles for active targeting to cancer cells: preparation, in vitro evaluation of targeting ability and cytotoxicity, Nanotechnology 19 (2008) 045102.

126.H. Li, Z.M. Qian, Transferrin/transferrin receptormediated drug delivery, Med. Res. Rev. 22 (2002) 225-250.

127.E.M. Kim, H.J. Jeong, I.K. Park, C.S. Cho, C.G. Kim, H.S. Bom, Hepatocyte-targeted nuclear imaging using 99mTc-galactosylated chitosan: conjugation, targeting, and biodistribution, J. Nucl. Med. 46 (2005) 141-145.

128.C. Zhang, Y. Cheng, G. Qu, X. Wu, Y. Ping, Z. Cheng, Yu Liangli, Q. Ping, Prepara and characterization of galactosylated cmitosan ated BSA microspheres cont ing 5-.uorot cil, Carbohyd. Polym. 72 (20^8) 3 , 397)

129.A. Gabizon, A.T. Horowitz, D. ren, D. Tzema F. Mandelbaum s it, M.M. Q n, S. Za psky, Targeting $\mathrm{f}$ ate $\mathrm{r}$ ptor with ate linked to extremitic of $\mathrm{p}$ (ethylene col)-grafted lip somes: in vitro st ies, Bioconjug. Chem. 10 (1 99) 289-298.

130.I Rotin, D. Steele-N, rood, S. Grinstein, I. $\mathrm{T}$ ock, Requiryment of the $\mathrm{Na}+\mathrm{H}+$ exchanger for tun growth, Cancer Res. 49 (1989) 205-211.

1.I.F. D. Rotin, Acid pH in tumors and its notential for therapeutic exploitation, Cancer Res. 49 ग9) 4373-4384.

132. T. Yahara, T. Koga, S. Yoshida, S. Nakagawa, H. Deguchi, K. Shirouzu, Relationship between microvessel density and thermographic hot areas in breast cancer, Surg. Today 33 (2003) 243-248.

133.H.C. Hurst, Update on HER-2 as a target for cancer therapy: the ERBB2 promoter and its exploitation for cancer treatment, Breast Cancer Res. 3 (2001) 395-398.

134.M. Stubbs, P.M. McSheehy, J.R. Grif.ths, Causes and consequences of acidic $\mathrm{pH}$ in tumors: a magnetic resonance study, Adv. Enzyme Regul. 39 (1999) 13-30.

135.M. Dellian, G. Helmlinger, F. Yuan, R.K. Jain, Fluorescence ratio imaging of interstitial $\mathrm{pH}$ in solid tumours: effect of glucose on spatial and temporal gradients, Br. J. Cancer 74 (1996) 1206-1215.

136.V.A. Sethuraman, M.C. Lee, Y.H. Bae, A biodegradable $\mathrm{pH}$-sensitive micelle system for targeting acidic solid tumors, Pharm. Res. 25 (2008) 657-666.

137.E.S. Lee, Z. Gao, Y.H. Bae, Recent progress in tumor $\mathrm{pH}$ targeting nanotechnology, J. Control Release 132 (2008) 164-170.

138.L. Fan, H. Wu, H. Zhang, F. Li, T. Yang, C. Gu, Q. Yang, Novel super $\mathrm{pH}$-sensitive nanoparticles responsive to tumor extracellular $\mathrm{pH}$, Carbohyd. Polym. 73 (2008) 390-400.

139.J.S. Park, T.H. Han, K.Y. Lee, S.S. Han, J.J. Hwang, D.H. Moon, S.Y. Kim, Y.W. Cho, Nacetyl histidine- 
conjugated glycol chitosan self-assembled nanoparticles for intracytoplasmic delivery of drugs: endocytosis, exocytosis and drug release, J. Control Release 115 (2006) 37-45.

140.H. Zhang, S. Mardyani, W.C. Chan, E. Kumacheva, Design of biocompatible chitosan microgels for targeted $\mathrm{pH}$-mediated intracellular release of cancer therapeutics, Biomacromolecules 7 (2006) 15681572 .

141.Q.A. Pankhurst, J. Connolly, S.K. Jones, J. Dobson, Applications of magnetic nanoparticles in biomedicine, J. Phys. D: Appl. Phys. 36 (2003) R167-R181.

142.E.E. Hassan, J.M. Gallo, Targeting anticancer drugs to the brain. I: enhanced brain delivery of oxantrazole following administration in magnetic cationic microspheres, J. Drug Target 1 (1993) 7-14.
143.L. Zhu, J. Ma, N. Jia, Y. Zhao, H. Shen, Chitosancoated magnetic nanoparticles as carriers of 5.uorouracil: preparation, characterization cytotoxicity studies, Colloids Surf. B., Bip terfaces 68 (2009) 1-6.

144.Y.C. Chang, D.B. Shieh, C.H. Chang, D.ł Chen, Conjugation of monodis rse chitosan und magnetic nanocarrier with ubicin for tar ed cancer therapy, J. Biomed.Nan (2005) 1 201.

145.Q. Yuan Ven asubramanià S. Hem, R.D. Misra, tilnulus-ro onsive magn nanoparticle dr/g cartier: ma etite encapsulated by itosangrafted- copo her. Acta Biomater. 4

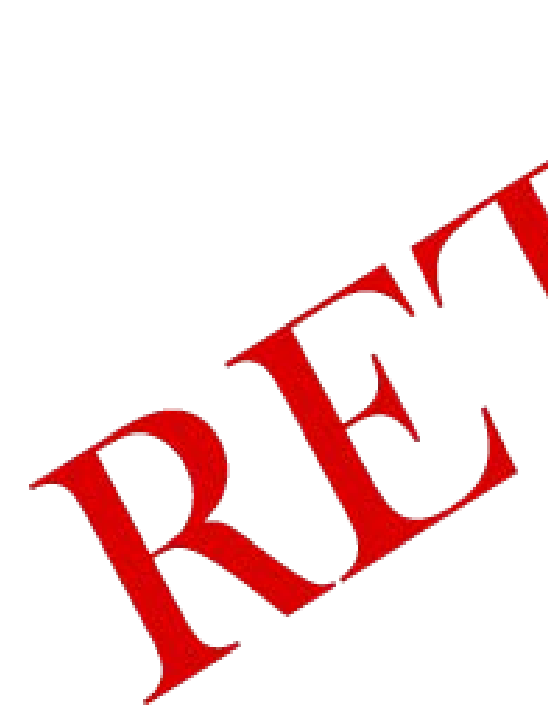

